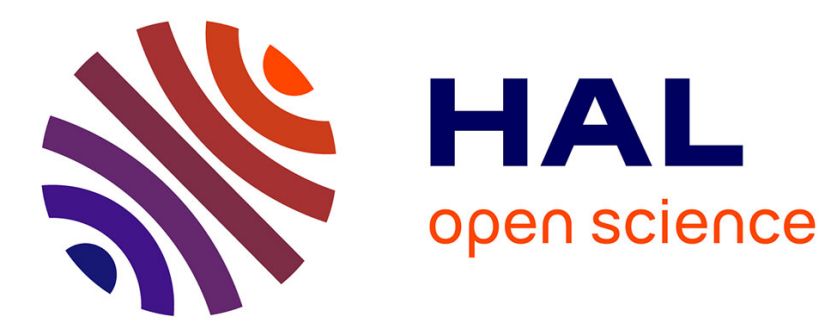

\title{
Price Stability and the ECB'S monetary policy strategy
}

Christian Bordes, Laurent Clerc

\section{To cite this version:}

Christian Bordes, Laurent Clerc. Price Stability and the ECB'S monetary policy strategy. Journal of Economic Surveys, 2007, 21 (2), pp.268 - 326. 10.1111/j.1467-6419.2006.00504.x . hal-00308557

\section{HAL Id: hal-00308557 https://hal.science/hal-00308557}

Submitted on 31 Jul 2008

HAL is a multi-disciplinary open access archive for the deposit and dissemination of scientific research documents, whether they are published or not. The documents may come from teaching and research institutions in France or abroad, or from public or private research centers.
L'archive ouverte pluridisciplinaire HAL, est destinée au dépôt et à la diffusion de documents scientifiques de niveau recherche, publiés ou non, émanant des établissements d'enseignement et de recherche français ou étrangers, des laboratoires publics ou privés. 


\section{NOTES D'ÉTUDES}

\section{ET DE RECHERCHE}

\section{PRICE STABILITY AND THE ECB'S}

\section{MONETARY POLICY STRATEGY}

Christian Bordes and Laurent Clerc

March 2004

NER \# 109

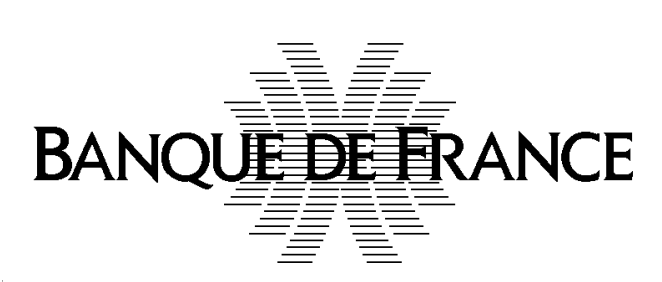




\title{
DIRECTION GÉNÉRALE DES ÉTUDES ET DES RELATIONS INTERNATIONALES DIRECTION DES ÉTUDES ÉCONOMIQUES ET DE LA RECHERCHE
}

\section{PRICE STABILITY AND THE ECB'S MONETARY POLICY STRATEGY}

\author{
Christian Bordes and Laurent Clerc
}

March 2004

NER \# 109

Les Notes d'Études et de Recherche reflètent les idées personnelles de leurs auteurs et n'expriment pas nécessairement la position de la Banque de France. Ce document est disponible sur le site internet de la Banque de France « www.banque-France.fr ».

The Working Paper Series reflect the opinions of the authors and do not necessarily express the views of the Banque de France. This document is available on the Banque de France Website "www.banqueFrance.fr". 


\title{
Price stability and the ECB's monetary policy strategy
}

\author{
Christian Bordes ${ }^{1}$ and Laurent Clerc $^{2}$
}

March 2004

\footnotetext{
${ }^{1}$ University of PARIS 1 - Panthéon - Sorbonne. E-mail : christian.bordes@ univ-paris1.fr

${ }^{2}$ Banque de France. E-mail : laurent.clerc2@banque-france.fr

The views expressed in this paper are those of the authors and not necessarily those of either the University of Paris 1 or the Banque de France. We thank the participants of the Banque de France research seminar for useful discussions and particularly our discussant Massimo Rostagno (ECB). Any remaining errors are our sole responsibility.
} 


\begin{abstract}
:
This paper focuses on the price stability objective within the framework of the single monetary policy strategy. It starts by reviewing what this objective, which is common to all central banks, means. Secondly, this paper will focus exclusively on the anchoring of short- to medium-term inflation expectations (Part 2). Several measures show that this anchoring is effective. Modern New Keynesian theory is an appropriate framework for analysing the impact that this anchoring of expectations has on the determination of the short- to medium-term inflation rate. From this point of view, observed inflation in the euro area seems to be in line with the theory and the ECB's action seems to be very effective. Thirdly, we will focus on the other aspect of monetary stability: the degree of price-level uncertainty and the anchoring of inflation expectations in the medium to long term. Even though this assessment is more difficult than it is in the short to medium term, since we only have a track record covering five years, various indicators from the theoretical analysis paint a fairly reassuring picture of the effectiveness of the device used by the ECB.
\end{abstract}

\title{
JEL Classification Number: E52, E58, E31
}

Keywords: Monetary policy, European Central Bank, Inflation 


\section{Non technical summary}

- Price stability needs to be examined using two criteria: a) the stability of short- to medium-term inflation expectations; b) the absence of long-term price-level uncertainty. In practice, unfortunately, assessments of monetary strategies are all too frequently limited to the first criteria.

- An inflation-targeting strategy is incomplete. It may ensure stability of the short- to medium-term inflation rate, but it cannot guarantee monetary stability in the long term. Therefore, another device is needed to supplement it.

- Central banks that have adopted an inflation-targeting strategy have not specified the exact nature of the other device, even though some of them have mentioned it. On the other hand, in the case of the ECB's strategy, which could be qualified as a "mixed" or "hybrid" strategy, the reference value for money growth should make it possible to regulate the price level in the long term.

- Since the single monetary policy was first applied, the short-term inflation dynamics has been disrupted by a series of temporary price shocks, but these shocks have not affected the anchor for inflation expectations, which have remained remarkably stable in a range between $1.5 \%$ and $2 \%$.

- The "New Keynesian" analytical framework is appropriate for the short to medium term: a policy to anchor inflation expectations is an effective instrument for ensuring monetary stability. Furthermore, money can provide helpful information about future economic activity and, to a lesser extent, about price developments.

- Short- to medium-term inflation in the euro area has been in keeping with the main tenets of economic theory. A rough empirical review shows that: 1) There seems to be strong persistence of inflation, which nevertheless seems to have abated substantially since the implementation of the single monetary policy. 2) The change in the monetary regime did not give rise to greater uncertainty about the short-term inflation dynamics, except for a fleeting moment during the cash changeover to the euro. 3) The ECB's monetary policy decisions seem to show that it has been less aggressive than New Keynesian theory would recommend (Taylor principle). However, the ECB's response could be explained by the special attention paid to long-term inflation expectations.

III

- The highlights of an empirical analysis of the medium- to long-term inflation dynamics in the euro area are as follows: 1) The average annual steady-state inflation rate would be about $1.9 \%$, which is "close to, but less than $2 \%$ ". The reversion to the steady state after a transient inflation shock is still quite slow. Reversion takes about seven years, because of the strong inertia of inflation. 2) The various measurements of long-term inflation expectations are consistent and stable in a range between $1.5 \%$ and $2 \%$. The stability of these long-term expectations meant that the ECB did not have to act very aggressively.

- New Keynesian analysis on its own cannot provide a satisfactory explanation of the anchoring of long-term inflation expectations. Money plays a decisive role in the long term. From this point of view, the ECB's announcement of a reference value for money growth is grounded on a sound theoretical basis.

- Yet it is difficult to assess the medium- to long-term effectiveness of the ECB's monetary policy strategy after only four years of operation. However, a preliminary empirical analysis reveals some fairly reassuring signs. 1) A shock that affects short-term inflation expectations usually does 
not have a knock-on effect on longer-term inflation expectations. 2) Since 1999, analysis has not rejected the hypothesis of price stationarity around a deterministic trend, which is a sign of longterm stability in the inflation rate and an absence of price-level uncertainty.

IV

- In terms of monetary policy strategy, the clarification provided at the end of the ECB Governing Council meeting on 8 May 2003 was useful in three respects in light of the conclusions of this report.

- The distinction drawn between "economic analysis", which refers to the New Keynesian analytical framework, and "monetary analysis" is a relevant one, because it makes it possible to anchor short-, medium- and long-term inflation expectations simultaneously.

- It solves a problem in communicating and even implementing the single monetary policy strategy. This strategy was based on a presentation of the two "pillars" as alternative explanations for inflation, which could end up giving money a role in stabilising short-term anticipations that it would be unable to play. In fact, the two approaches are complements to each other rather than alternatives. Money plays a decisive role in anchoring long-term inflationary expectations, while the New Keynesian framework is adequate for analysing short-term expectations. This means that the change in the structure of the ECB President's introductory statement following each Governing Council meeting will fully reflect the complementary nature of the two analytical frameworks.

- Finally, the anchoring of inflation expectations stemming from the announcement of the reference value and from the European Central Bank's credibility ensures that there is no long-term pricelevel uncertainty. This means that monetary policy does not necessarily have to compensate for a deviation from the inflation path in the short term, since the reversion to the equilibrium path should be achieved via expectations. 


\section{Introduction}

This paper focuses on the price stability objective within the framework of the single monetary policy strategy. It starts by reviewing what this objective, which is common to all central banks, means (Part 1). It encompasses two very distinct characteristics (Ireland, 1993): a) the anchoring of short- to medium-term inflation expectations; b) the absence of long-term price-level uncertainty. The ECB's monetary strategy is aimed at achieving both objectives simultaneously in the euro-area economy. Secondly, this report will focus exclusively on the anchoring of short- to medium-term inflation expectations (Part 2). Several measures show that this anchoring is effective. Modern New Keynesian theory is an appropriate framework for analysing the impact that this anchoring of expectations has on the determination of the short- to medium-term inflation rate. From this point of view, observed inflation in the euro area seems to be in line with the theory and the ECB's action seems to be very effective. The third part of this report will focus on the other aspect of monetary stability: the degree of price-level uncertainty and the anchoring of inflation expectations in the medium to long term (Part 3). The approach used in Part 2 of the report is used again in Part 3. We start with an empirical analysis aimed at revealing the steady-state inflation rate. This analysis reviews the various measures of expected long-term inflation in the euro area. The theoretical framework used in Part 2 is then supplemented by highlighting the role played by the announcement of a reference value for the growth of the money supply, which is intended to anchor long-term inflation expectations. This framework is then used to assess the effectiveness of the ECB's action to ensure monetary stability in the long term. Even though this assessment is more difficult than it is in the short to medium term, since we only have a track record covering five years, various indicators from the theoretical analysis paint a fairly reassuring picture of the effectiveness of the device used.

As we can see, the analysis of monetary stability in the euro area hinges on the distinction between short- to medium-term developments on one side and the long-term prospects on the other. For the analysis to be complete, we need to look at each of these two aspects in turn, even though most of the available research all too frequently focuses exclusively on the first. What does this distinction mean in practice? The ECB mentions it explicitly when announcing its determination to control mediumterm inflation in the euro area. Some observers have expressed regret that the ECB does not provide an operational definition of the medium term, but, at the same time, they state that it is by no means certain that such a definition could be provided (Gali, 2003). This point of view is probably excessive. A clear definition emerges from the research on the subject. Based on empirical studies of the relationships between money, economic activity and prices, we can agree on the following definitions (Issing et al, 2000; Jaeger, 2002): The short term is a period from one and a half to two years, during which money mainly influences economic activity. The medium term corresponds to a complete business cycle, lasting around five years. The long term is a period of eight to ten years, at least, during which the neutrality of money manifests itself, since variations in the money supply affect only the price level.

\section{Monetary stability and the ECB's strategy}

\subsection{What is monetary stability?}

Strictly speaking, price stability is defined by two conditions: a) an absence of long-term price-level uncertainty; and b) an expected inflation rate of zero (Ireland 1993). The definition used in practice is often less strict. The second condition is not that stringent. Problems involved in measuring price increases accurately mean that a slightly positive expected inflation rate is deemed to satisfy this condition, as long as it is more or less constant. Some observers go even further and settle for fulfilment of the second condition and ignore the first condition. Price stability is therefore defined as a situation where "expected changes in the average price level are small enough and gradual enough that they do not materially enter business and household financial decisions" (Greenspan, 1989). 
The pure and amended forms of the second condition are justified by the institutional approach that stresses the vulnerability of central banks in democratic societies. This approach was initially proposed by Kydland and Prescott (1977) and later developed by Barro and Gordon (1983). It is now expressed in the form of the expectations trap hypothesis to explain inflation dynamics (Christiano and Gust 2000; Christiano and Fitzgerald, 2003). If economic agents expect a high inflation rate, they take protective actions and the monetary authorities are faced with the following dilemma (Chart 1).

- $\quad$ They can validate the expectations by increasing money growth, which allows them to avoid a recession, but at the cost of higher inflation.

- $\quad$ They can abstain from increasing money growth, thus avoiding higher inflation, but inducing recession.

If the central bank is to avoid this trap and ensure monetary stability, it must make it clear that the first scenario must be ruled out. This is much easier to do if the central bank is independent from the government. But regardless of the central bank's status, everything depends on its strategy. Prompt and decisive action in response to a substantial change in price-level expectations, meaning both inflation and deflation expectations, prevents the triggering of chain reactions that can quickly spin out of control. This calls for constant monitoring of the available indicators. The effectiveness of the authorities' action can be assessed by examining developments in the expected inflation rate, as measured by surveys or indicators constructed from financial market data. As the observed inflation rate is equal to the expected inflation rate in the medium to long term, the first condition is deemed to hold when the $(\log )$ price level is stationary around a trend line.

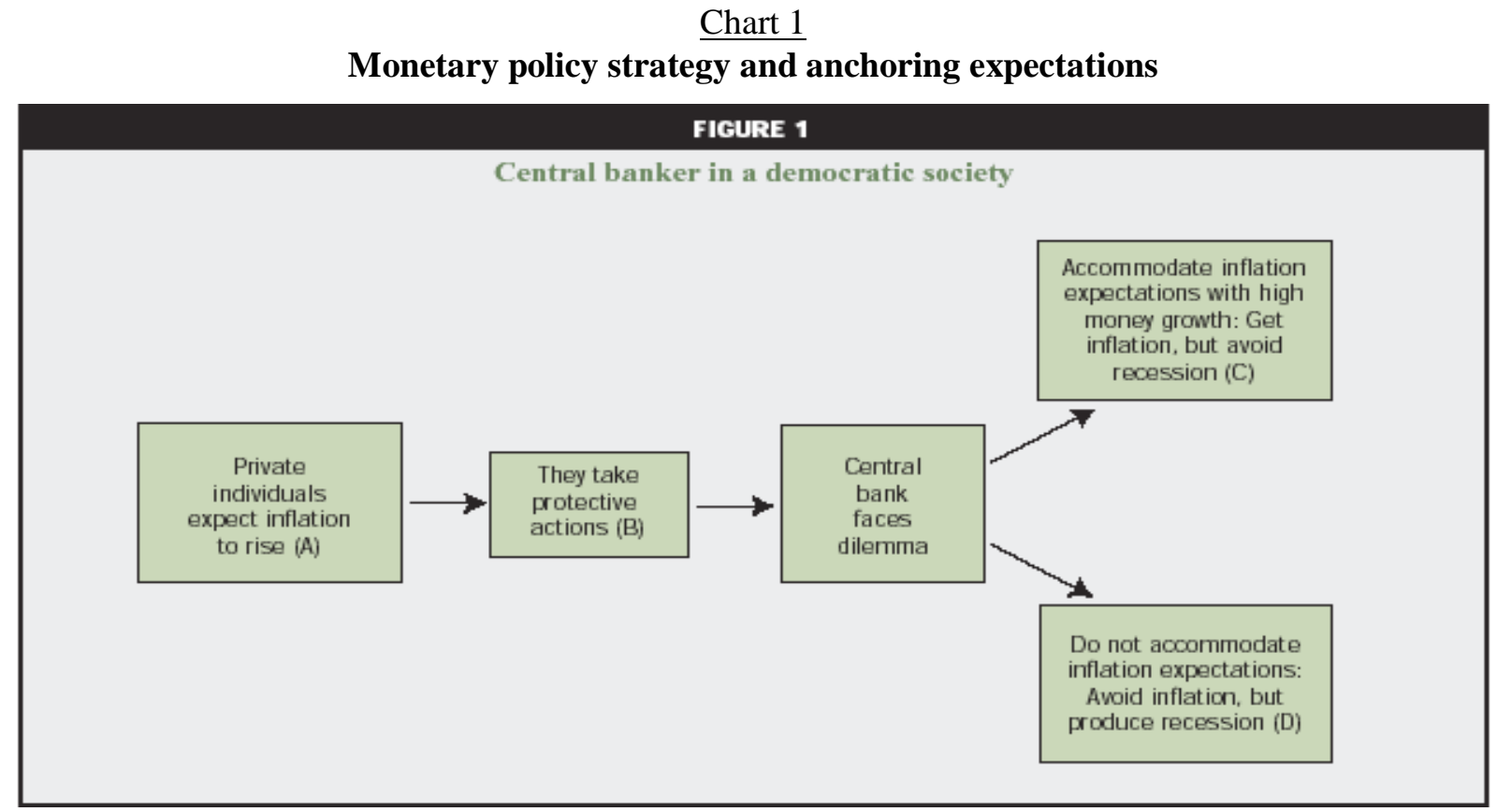

Source: Christiano and Fitzgerald (2003) p. 24.

The first condition indicates that long-term price-level developments should be as steady as possible. ${ }^{3}$ There are many advantages to long-term price stability. It eliminates arbitrary wealth transfers, it reduces calculation and menu costs, it enhances the role that prices play in the allocation of resources and it eliminates the distortions of a tax system that applies to nominal values (see, for example, Barnett and Engineer, 1999)."With long-term inflation expectations more firmly anchored, long-term interest rates might jump around a bit less, and businesses and investors might find it easier to draw up long-term contracts" (Rogoff, 2003). Any uncertainty in this area makes decision-making more

\footnotetext{
${ }^{3}$ At this point, the definition of the long term is still fairly vague. It ranges from at least ten years to an average of twenty years. This definition is set out in 2.1 .
} 
difficult. Money does not fulfil its role of unit of account as well as it should and this penalises economic agents, including households saving for retirement and businesses that have to borrow shortterm funds, since risk premiums make long-term financing more expensive. Consequently, deviations from the trend line, corresponding to the anchoring of expectations on a given value, must not be too large, otherwise uncertainty in the economic climate will increase and hamper investment and growth.

As we have already mentioned, this characteristic of monetary stability is often overlooked. At first glance, this may seem only right; if inflation expectations are always anchored and, if there are no shocks to the economy, then there is no price-level uncertainty. Naturally, the real world is different. Central banks cannot control prices so strictly, nor do they want to, because, if they did and a shock occurred, they would have to accept major fluctuations in economic activity. This means that inflation may be higher or lower than expected over periods of varying lengths. If we consider that such deviations become permanent, meaning that the central bank does not attempt to correct past deviations, then long-term price-level developments become uncertain, despite the stability of inflation expectations. Consequently, we need to assess the success of a monetary stability strategy using the two criteria described at the outset.

\subsection{Monetary stability programmes: the options available}

The usual form of inflation target can be used to anchor expectations, but it does not ensure monetary stability in the full meaning of the term. This requires a supplementary device aimed at reducing longterm price-level uncertainty. On the other hand, a "Friedman" monetary rule would limit such uncertainty, but it could not ensure sufficiently solid anchoring of short-term expectations. In theory, the simplest solution to this problem is to set a price-level target. But this would entail other problems, which we shall discuss later. In practice, the solution is to adopt a mixed, or hybrid, strategy, where anchoring of expectations is backed up by a device that acts to force the price level back toward a regular trend (McCallum, 1997; Batini and Yates, 2001; Mishkin, 2000). Periodic review of the inflation target, or else the use of a reference value for money growth, can be considered as means towards this end. ${ }^{4}$

\subsubsection{Incomplete strategies: inflation targets or money growth rules}

Many central banks have opted for an inflation target. They adjust the interest rate according to expected developments in inflation at a time horizon that is generally between eighteen months and two years ahead. This strategy is an effective way of anchoring inflation expectations over the period concerned. But it may also entail a great deal of long-term price-level uncertainty (see Goodfriend, 1987). Inflation may in fact be higher or lower than expected. If we consider that deviations from the constant path are permanent, as is usually the case, the trend in the price level may be irregular in the long term, even though there is solid anchoring of inflation expectations in the shorter term. Everything depends on whether this volatility creates troublesome uncertainty that could disrupt the functioning of the economy. Some observers think that this is not the case. They use the following arguments (McCallum, 1997, pp. 18-19): a) few economic decisions are based on planning horizons over twenty years ahead; b) price-level uncertainty twenty years in the future is not large, even if the $\log$ price level behaves as a random walk. A confidence interval at the usual level of $95 \%$ would be only (plus or minus) $8 \%$ for the log price level at this horizon. This corresponds to a very low level of uncertainty compared to that observed in the nineteen-sixties through the nineteen-eighties. But, even if we accept this argument, which not all analysts do, the hybrid strategy is still better, because it provides the advantages of stationarity of the price level around a trend (McCallum, 1997, p. 19).

Friedman (1960) proposed a constant-rate money supply growth rule. This rule should make a regular long-term trend in the price level possible if the relationship between money supply and prices is

\footnotetext{
${ }^{4}$ The list of hybrid strategies is longer. Mishkin (2000) suggests two others: 1) announcing an inflation target with a commitment to some error correction in which target misses will be offset to some extent in the future; 2) pursuing an inflation target under normal conditions, but providing for an escape clause that puts in place a price-level target in the event that deflation threatens, particularly if interest rates are near $0 \%$.
} 
stable over the period. To achieve this, the velocity of circulation and the economic growth rate must not be affected by permanent shocks. Even if we assume that this is the case, the relationship between money and prices cannot hold over a shorter period. This means that this strategy may have difficulty providing a solid anchor for expectations at all times. It is also in contradiction to the real-world situation, where central banks' actions are taken in a short-term perspective and are aimed at controlling interest rates rather than the growth of a monetary aggregate.

\subsubsection{Price-level targeting}

A central bank may choose to announce a growth path for the price level, which is the same as setting a target for the average long-term inflation rate. The bank then attempts to correct deviations of the observed growth path from the preset growth path. The success of this strategy can be measured by the stationarity of the $\log$ price-level series around a linear trend. In this case, both characteristics of monetary stability can hold at the same time. One of the main advantages of this strategy would be to shelter the economy from the threat of deflation by curbing any price drift. If prices do fall, inflation expectations will automatically be revised upwards (Svensson, 1999). On the other hand, output and inflation would be more volatile than they would under an inflation-targeting regime. The reason for this is simple: when a shock pushes inflation up over its average trend, the inflation rate has to fall below the average later on. If the economy has nominal rigidities, the greater variability of the inflation rate would give rise to greater variability in output. However, this idea has been called into question by recent research showing that, under certain conditions relating to the formation of expectations and the persistence of output, this strategy can ensure greater long-term price stability without increasing the volatility of output (see Barnett and Engineer, 1999).

\subsubsection{Combination of an inflation target and a price level target}

King (1996) proposes a mixed strategy, with an inflation target for one and a half to two years ahead, along with periodic assessments every five years of the price level and a calculation of the average inflation rate for the period under review. In practice, this is the same as adopting an interest-rate rule to correct deviations of the observed inflation rate from the target for short- to medium-term inflation, as well as correcting the deviations of the observed variations from the desired price level. The pricelevel correction occurs at a more distant horizon of ten or more years ahead. In this case, interest rates are set according to the following rule:

$i_{t}=i^{*}+\lambda_{1}\left(y_{t}-y^{*}\right)+\lambda_{2}\left(\pi_{t}-\pi^{*}\right)+\lambda_{3}\left(\frac{P_{t}-P_{t}^{*}}{P_{t}^{*}}\right)$

where: $\lambda_{3}=\lambda_{2} / \mathrm{H}$ and $\mathrm{H}$ denote the time horizon; $\mathrm{y}_{\mathrm{t}}-\mathrm{y} *$ is the output gap; $\pi_{\mathrm{t}}-\pi *$ is the deviation of observed inflation from the inflation target; $\mathrm{P}_{\mathrm{t}}-\mathrm{P}^{*}$ is the deviation of the observed price level from the desired price level. ${ }^{5}$

\subsubsection{Anchoring inflation expectations and the reference value for money growth.}

Hetzel $(1987,1993)$ proposes some amendments to the strategy advocated by Friedman. Hetzel's proposal, like Friedman's, is based on the quantity theory of money and the principle of his proposal is derived from the same theory. But Hetzel amends and completes the theory on the basis of the observation that, in modern economies, the central bank does not have direct control over the quantity of money. Instead it controls the interest rate. According to the quantity theory of money, the central bank has to keep the interest rate at its equilibrium value in order to ensure price-level stability. This means that the central bank: a) adjusts its interest rate according to variations in the real interest rates; b) sets the interest rate so that the private sector can predict the future price level. In practice, the monetary authorities adjust the interest rate according to the deviation of the price-level path expected

\footnotetext{
${ }^{5}$ Batini and Yates (2001).
} 
by the private sector from the desired path, as measured, for example, via information provided by the index-linked bond market. At the same time, the authorities monitor money supply growth. The main difference with the previous strategy is that, if variations in money supply growth precede price-level changes, then the variable should be forced back toward the preset long-term path sooner. The ECB has chosen this type of strategy.

\subsection{The ECB's strategy}

\subsubsection{Hybrid strategy to ensure monetary stability}

The monetary policy strategy of the ECB is price-stability oriented. The ultimate objective is defined in the Maastricht Treaty, where Article 105 (1) stipulates, "The primary objective of the ESCB shall be to maintain price stability. Without prejudice to the objective of price stability, the ESCB shall support the general economic policies in the Community with a view to contributing to the achievement of the objectives of the Community as laid down in Article 2. ${ }^{6}$ The ESCB shall act in accordance with the principle of an open market economy with free competition, favouring an efficient allocation of resources, and in compliance with the principles set out in Article 4."'

After its meeting of 13 October 1998, ${ }^{8}$ the Governing Council of the ECB described the main elements of its monetary policy strategy. From the outset, this strategy has hinged on: a) a quantitative definition of the price stability objective assigned to the ECB by the Maastricht Treaty, "a year-onyear increase in the Harmonised Index of Consumer Prices (HICP) for the euro area of below 2\%"; $b$ ) an analysis that assigns a "prominent role for money" signalled by the announcement of a reference value, ${ }^{9}$ and based on "a broadly-based assessment of the outlook for price developments [...] using a wide range of economic and financial variables". The editorial in the first issue of the ECB Monthly Bulletin in January 1999 made this "two pillar" approach official.

Furthermore, the Governing Council's definition stipulates that: a) price stability needs to be maintained in the medium term, thus acknowledging that there is short-term price volatility that cannot be controlled by monetary policy; b) the emphasis is placed on the HICP "for the euro area", since monetary decisions are made according to developments relating to the euro area as a whole and not to specific regions or countries; c) the $2 \%$ threshold is the same as that previously targeted by most of the central banks in the euro area. With respect to the last point and in response to criticisms of the asymmetrical character of the definition, the ECB later explained that the expression "year-on-year increase in prices" automatically ruled out situations where prices fall (i.e. deflation).

Even though it really has not been called into question, except for some critics who would like to replace it with core inflation, the appropriateness of the choice of the HICP as the reference indicator for the quantitative definition of price stability was upheld during the internal evaluation exercise carried out in the Eurosystem (Camba-Mendez, 2003). The HICP has many advantages, such as its availability. It is one of the only harmonised indices calculated for the euro area as a whole. This automatically ensures comparability of prices across the European Monetary Union. The HICP also enjoys full credibility as a recognised and accepted measurement of price-level changes and it is available on a monthly basis. However, the HICP also has some shortcomings. It could be improved through more frequent revisions of the weights used at national level. In fact, only five out of the

\footnotetext{
${ }^{6}$ Article 2 stipulates that "The Community shall have as its task [...] to promote throughout the Community a harmonious, balanced and sustainable development of economic activities, a high level of employment and of social protection, [...] sustainable and non-inflationary growth, a high degree of competitiveness and convergence of economic performance, a high level of protection and improvement of the quality of the environment".

${ }^{7}$ In particular, Article 4 stipulates that the activities of the Member States and the Community shall include "the definition and conduct of a single monetary policy and exchange-rate policy the primary objective of both of which shall be to maintain price stability and, without prejudice to this objective, to support the general economic policies in the Community, in accordance with the principle of an open market economy with free competition."

${ }^{8}$ See the Press Release dated 13 October 1998: “A stability-oriented monetary policy strategy for the ESCB”.

${ }^{9}$ See the Press Release dated 1 December 1998: "The quantitative reference value for monetary growth".
} 
twelve countries revise their weights on an annual basis. Furthermore, it is impossible to measure the margin of error in the measurement of prices in the euro area accurately.

In their reports to the French Council of Economic Analysis, Artus and Wyplosz (2002) state that the ECB's inflation target of $2 \%$ is too low and that the implicit target range is too narrow. They recommend adopting range of $1 \%$ to $4 \%$ instead. Paul De Grauwe (quoted in an article in Le Monde, 29 January 2003, "La banque centrale européenne s'interroge sur son rôle") suggests a smaller range of $2 \%$ to $3 \%$. In a series of papers, Svensson $(2002 ; 2003)$ maintains that the Eurosystem's definition of price stability is ambiguous and asymmetrical and that it is less effective for anchoring expectations than a point target would be. He argues that an explicit and symmetrical point inflation target of $1.5 \%$, $2 \%$ or $2.5 \%$ would be better and would provide a better anchor for inflation expectations. He also argues that, as long as a target value is announced clearly, it does not matter whether there is a range or not (Svensson, 2002).

But the most important thing is that the ECB's strategy focuses on both aspects of monetary stability. This means that it can be regarded as a hybrid strategy aimed at anchoring medium-term inflation expectations, while simultaneously seeking to reduce long-term price-level uncertainty. As Jaeger (2002) so rightly stated, it can be seen as "a modified version of an inflation target, where the central bank avoids announcing a precise value or range for the medium-term inflation rate, while using an explicit nominal anchor (the reference value for M3 growth) to shape long-term inflation expectations".

\subsubsection{Real determinants of inflation and anchoring short- to medium-term expectations}

In the short to medium term, the ECB's monetary strategy stresses the role of the real determinants of inflation. This strategy is based on the widely accepted idea that monetary policy influences inflation in the following manner: changes in key interest rates influence short-term interest rates, short-term expectations with regard to economic activity and, through them, price-level changes. If follows that "a broadly based assessment of the outlook for prices and the risks to price stability in the euro area will play a major role in the Eurosystem's strategy" (ECB, 1999a, p. 49). The appropriateness of monetary policy shall be assessed by considering inflation forecasts derived from wages, exchange rates, bond prices and the yield curve, various measures of real activity, price and cost indices and surveys of businesses and consumers.

\subsubsection{Monetary determinants of inflation and anchoring medium- to long-term expectations}

The ECB's monetary strategy is also intended to anchor medium- to long-term expectations. "The statement that 'price stability is to be maintained over the medium term' reflects the need for monetary policy to have a forward-looking, medium-term orientation" (ECB, 1999a, p. 47, the emphasis is ours). The choice of method is based on the idea that monetary policy transmission mechanisms via the real sector are not the only channels through which the central bank influences prices. "There is broad consensus, based on substantial empirical evidence, that the development of the price level is a monetary phenomenon in the medium to long term" (ECB, 1999b, p. 29, the emphasis is ours). Over this period, "money constitutes a natural, firm and reliable 'nominal anchor' for monetary policy aiming at the maintenance of price stability" (ECB, 1999a, p. 47, the emphasis is ours). This means that money is given an important role through the announcement of a reference value for the growth of a monetary aggregate. "However, the concept of a reference value does not entail a commitment on the part of the Eurosystem to correct deviations of money growth from the reference value over the short term" (ibid. p. 48).

The ECB's ability to anchor long-term inflation expectations has been the subject of much controversy. The critics are particularly severe with the core of the ECB's monetary policy strategy. They generally advocate an alternative inflation-targeting strategy in its place. In a review of the practices and results of fifteen OECD countries' central banks, Castelnuovo et al. (2003) show that most of these central banks, with the notable exception of Japan, have managed increasingly to anchor 
agents' long-term inflation expectations. ${ }^{10}$ This finding does not seem to depend on the strategic framework or on the way the inflation target is specified (i.e. as a point target or a range). To a certain extent, this research confirms the conclusions of Ball and Sheridan (2003), who cast doubt on the superiority of inflation-targeting strategies when it comes to stabilising prices, output and interest rates.

But, at what level should these inflation expectations be stabilised? The literature on finding the optimal inflation rate has basically split into two camps, between those that think that inflation acts like sand in the gears, slowing the economy down, and those who believe that it acts like grease. Generally speaking, empirical research shows that there is a negative relationship between growth and inflation, but that this relationship holds at relatively high levels of inflation. On the other hand, a recent paper by Rodriguez-Palenzuela et al (2003) shows that, in the case of the euro area, moderate levels of inflation would also produce "sand effects". Yet, the euro area seems to be characterised by major nominal rigidities, which hints that even a low rate of inflation could promote flexibility in real wages and thus contribute to adjustment in the labour and goods markets, and ultimately boost growth. However, Coenen (2003b) uses a small macroeconomic structural model calibrated to fit the euro area to show that the impact of these nominal rigidities is small and that it is probably not significant for inflation rates over $1 \%$.

However, the choice of an excessively low inflation target entails the risk of being confronted with the zero lower bound on nominal interest rates in the event of a major exogenous shock to the economy. Low inflation and its corollary, low nominal interest rates, limit the potential of the central banks' main instrument. The banks cannot lower their official rates far enough, which means that real rates cannot fall enough to offset the effects of an unfavourable shock on the economy. Furthermore, when nominal interest rates are near zero, a deflationary shock could lead to a rise in real interest rates, which would be harmful for the economy. Simulations conducted using models calibrated to fit the euro area tend to show that the likelihood of running up against the zero constraint on nominal interest rates becomes negligible with an inflation target of $1 \%$ or more (Klaeffling and Perez, 2003). However, these results depend heavily on assumptions about the wage-setting procedures. More specifically, when wages are set in accordance with Taylor's model ${ }^{11}$ (1979), the probability of running up against the zero constraint is less than $7 \%$, if the inflation target is between $1 \%$ and $2 \%$. On the other hand, the probability is no longer negligible when wage contracts are fixed in accordance with the model proposed by Fuhrer and Moore ${ }^{12}$ (1995). When the inflation target is zero, the probability is about $30 \%$. It stands at $25 \%$ for a target of $1 \%$ and $17 \%$ for a target of $2 \%$ (Coenen, 2003a). Under the specifications for the second model, the existence of inflation rigidities, in addition to price rigidities, means that a fall in inflation entails a drop in activity, whereas, in the first model, lower inflation has no effect on output.

On 8 May 2003, the ECB presented the conclusions of an evaluation of its strategy. The evaluation was motivated by a determination to review its performance after four years of operation. The evaluation was intended as a response to the questions and comments of outside observers and it takes into account the findings of research by ECB staff. With regard to the price stability objective, which is the only one that interests us here, the Governing Council discussed the matter and decided to uphold the $2 \%$ upper bound for the inflation rate, as measured by the HICP. It also stated its "aim to maintain inflation rates close to, but below, $2 \%$ in the medium term". It considered the costs of inflation and the need to maintain a sufficient safety margin to guard against the risks of deflation. It also addressed the issue of the possible measurement bias in the HICP and the implications of inflation differentials within the euro area.

\footnotetext{
${ }^{10}$ The long-term inflation expectations (10 years) are taken from the Consensus Forecast.

${ }^{11}$ In this model, wages are set over the two periods and prices are determined by a constant mark-up on wages. This model induces price rigidity but not inflation rigidity.

${ }^{12}$ Unlike the previous model, this one assumes that there is also inflation rigidity.
} 


\section{Anchoring short- to medium-term expectations and inflation dynamics}

What influence has the ECB's monetary policy had on the euro area inflation rate in the short to medium term? We cannot answer this question without reference to an analytical framework. We shall present this framework after reviewing historical and expected inflation developments since 1999. The framework is then used to interpret these developments, with an effort to reveal the ECB's contribution to price stability and its influence on inflation dynamics.

\subsection{Short-term inflation and inflation expectations in the euro area}

\subsubsection{Inflation level: Harmonised Index of Consumer Prices}

The Harmonised Index of Consumer Prices is the general price level measure that the ECB uses to measure inflation in the euro area. This choice is explained by: a) the extensive harmonisation of the index across the countries in the euro area; b) its availability and c) the important role it plays in economic agents' decision-making. But this index may be volatile at times when some of its components, such as food or oil prices, are affected by temporary shocks that do not influence the rate of inflation in the medium to long term, which is the type of inflation that concerns the monetary authorities. Sometimes, a measure of the core or underlying inflation rate is used to get around this problem. For example, the Bank of Canada uses a consumer price index that is adjusted for changes in indirect taxes (Core CPI). There is a core inflation index for the euro area that excludes prices for energy and fresh food.

Chart 2 shows the monthly variations in the year-on-year inflation rate from 1993Q1 to 2003Q3. There are three easily discerned stages. Up until 1999, the convergence of national inflation rates on the lowest rates led to a steady fall in average inflation. The single monetary policy was initiated in a very favourable environment, coinciding with a fall in inflation. This was mainly due to declines in energy prices, unit wage costs and commodity prices on world markets (see, for example, Hayo, Neumann and von Hagen, 2002). Later on, the situation was reversed and supply conditions deteriorated as productivity gains slowed, diseases affected livestock, and oil prices and relative service prices rose (see Artus, 2002). Then, after 2001, inflation resumed its downward trend but there were episodes of increased volatility.

The same chart shows year-on-year changes in core inflation too. The comparison with the HICP clearly shows the impact of temporary shocks at the end of 1999 and during 2000.

Chart 2

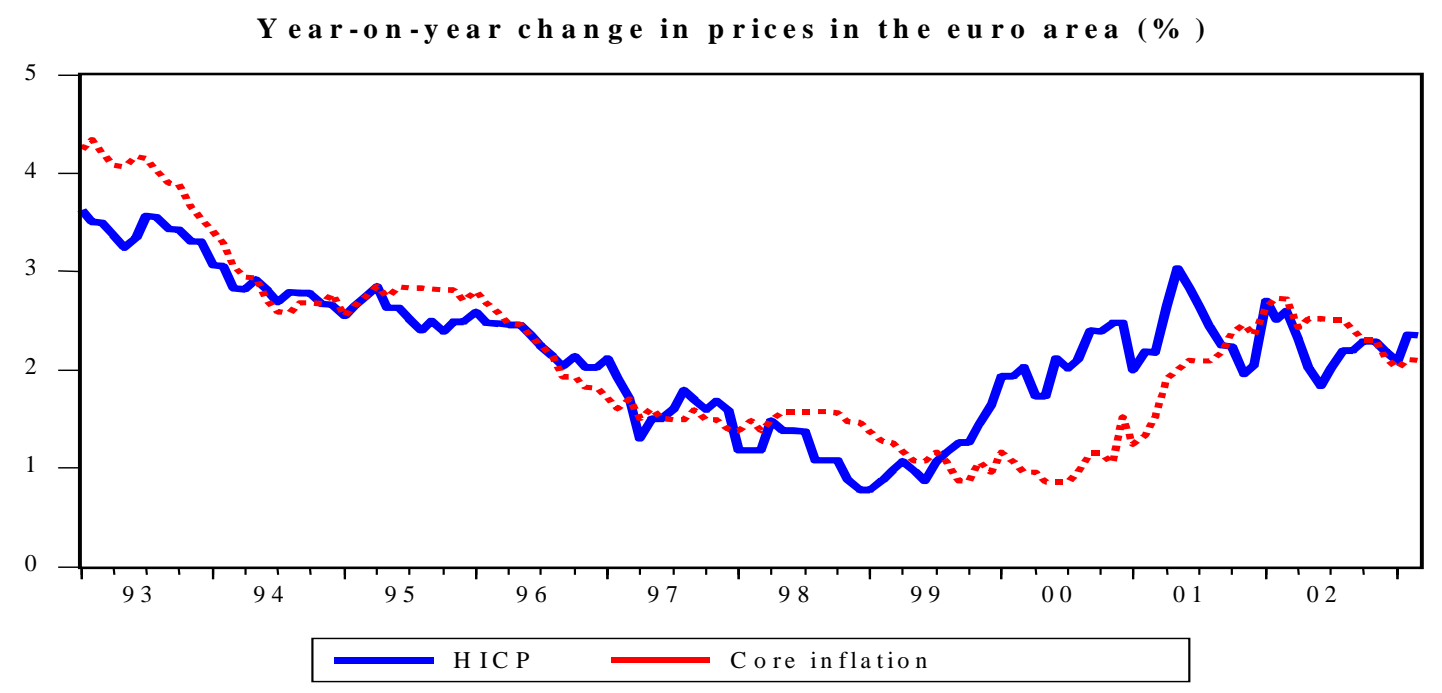




\subsubsection{Short-term inflation expectations}

Inflation expectations can be measured at different levels: consumers or producers, through business conditions surveys; economists or forecasters, through surveys and questionnaires aimed at aggregating their views on current or future activity and price developments; directly on financial markets by deriving inflation expectations from yields on index-linked bonds.

Consumers' inflation expectations are a good leading indicator for future inflation, with a lag of about one year (see Forsells and Kenny, 2002).

Opinion surveys show that households' very-short-term inflation expectations seem to move in parallel to observed inflation. However, since the beginning of 2002, there has been a gap between the inflation as it is perceived by households and observed inflation. However, the divergence of trends relating to perceived inflation and expected inflation testifies to solid anchoring of European consumers' short-term inflation expectations. But it also shows how difficult it is to interpret these consumers' opinion clearly.

\section{Chart 3}

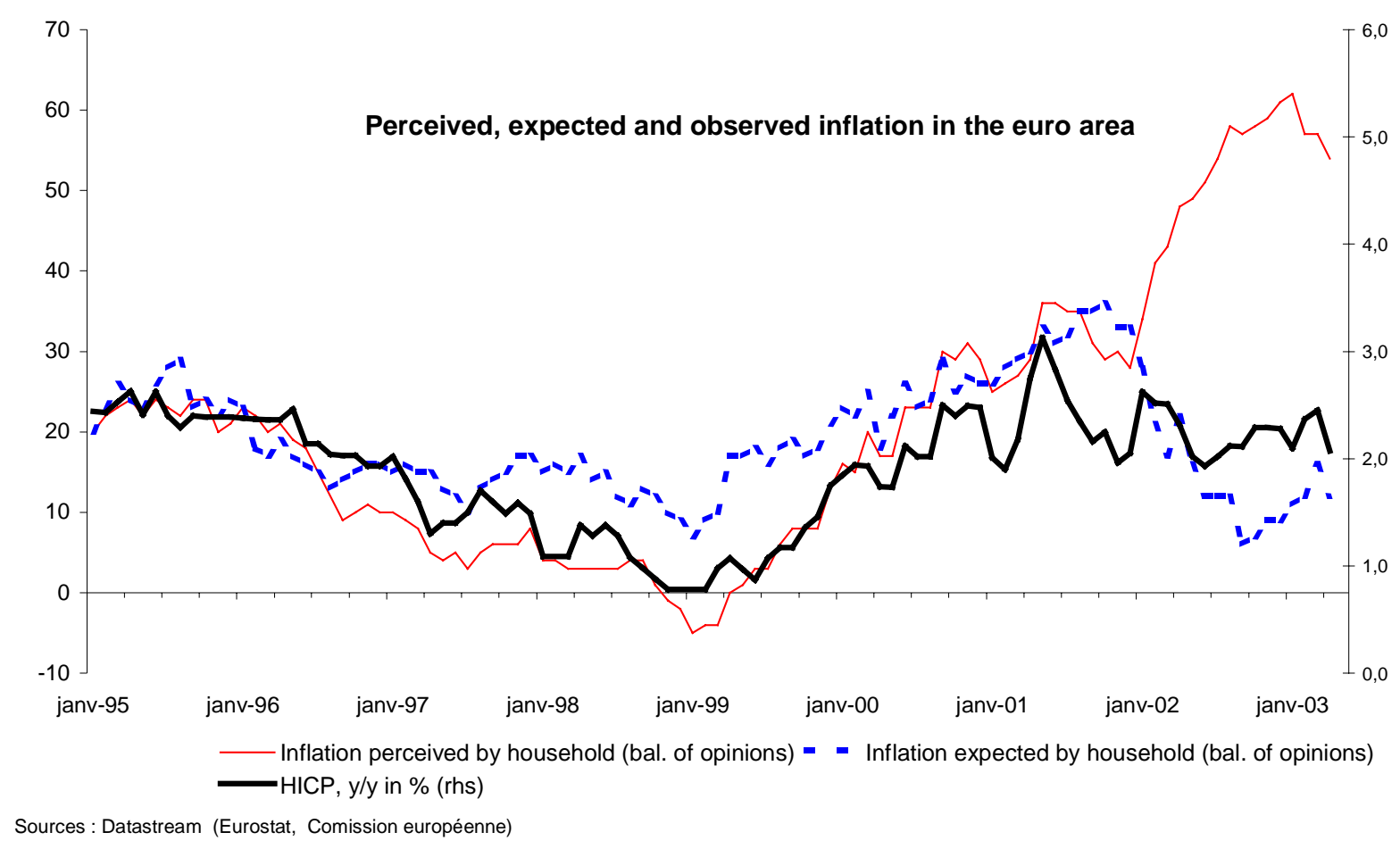

Surveys of economists and forecasters are a second source of information. Since early 1999, the ECB staff has conducted a quarterly survey of a panel of professional forecasters from the private sector. ${ }^{13}$ One special feature of this survey is that the forecasters are asked directly to assign a distribution of probabilities to various future inflation rates in the euro area for the current year and up to four years ahead. Charts 4 below shows the average inflation forecasts of the panel at different time horizons and Chart 5 shows the changes in the individual mean probability distributions. Whether we consider the mean expectations in Chart 4 or the distributions in Chart 5, we see that the forecasters' inflation expectations for the euro area seem to be particularly solidly anchored in the short to medium term, as are those of households.

\footnotetext{
${ }^{13}$ The results of the survey are available on the ECB's web site: $\underline{w w w . e c b . i n t}$
} 


\section{Chart 4}

ECB Survey of Professional Forecasters: mean inflation

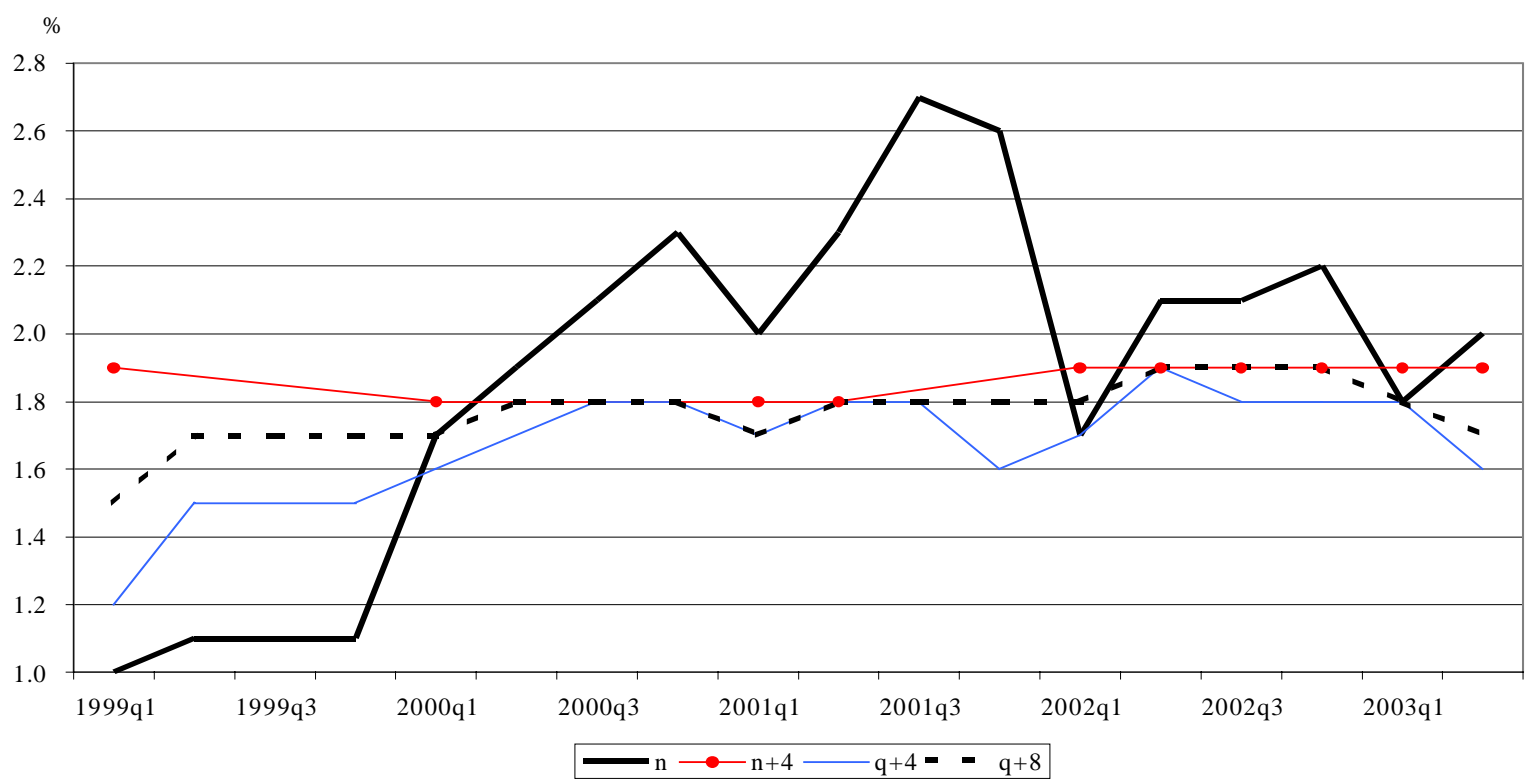

The above Chart shows that the forecasters predictions for the current year mirror the many supply shocks that marked the first four years of the single monetary policy, but their inflation expectations tend to fall within a range that narrows as the forecast horizon becomes more distant. At one year ahead (i.e. four quarters from the present, the " $\mathrm{q}+4$ " series, expected inflation ranges between $1.2 \%$ and $1.9 \%$ from the first quarter of 1999 to the last available survey in the second quarter of 2003. This range narrows to $1.5 \%$ to $1.9 \%$ when we look at the two-years-ahead forecast (" $q+8$ " series) and in the four-years-ahead forecast ( $\mathrm{n}+4$ series), the predictions look remarkably stable and firmly anchored between $1.8 \%$ and $1.9 \%$.

Changes in the mean individual probability distributions (Chart 5) also show the same gradual trend towards stabilisation of short- to medium-term inflation expectations since implementation of the single monetary policy started.

The mean probability distribution of the forecasts for the short to medium term (up to 4 years ahead) also appears to be remarkably stable. Since the beginning of the survey, the mode has always been between $1.5 \%$ and $1.9 \%$. The mean probability that the forecasters give for the inflation rate falling within this range is practically constant at nearly $40 \%$.

The same holds true for one-year-ahead inflation forecasts, where forecasters give a slightly higher probability of the inflation rate falling within the 1.5\%-to-1.9\% range, which may suggest that they expect the ECB to respond quite rapidly to current price shocks.

The only distributions that fall outside the 1.5\%-to- $1.9 \%$ range are those relating to the current year, because they take account of several shocks. For example, the surveys in the first quarter of 1999 and the first quarter of 2001, as well as the one in the second quarter of 2003, show that the current price dynamics do not materially affect the distribution of inflation expectations, either when they are weak, as was the case in 1999, or when they are strong, as was the case in 2001 and 2003. 


\section{$\underline{\text { Chart } 5}$}

\section{ECB's Survey of Professional Forecasters: mean probability distributions}

for inflation forecasts from different surveys

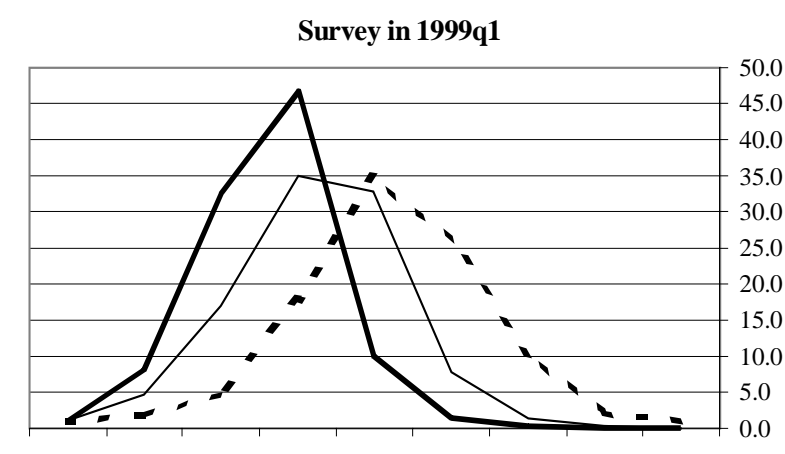

$<0.0 \quad 0.0-0.4 \quad 0.5-0.9 \quad 1.0-1.4 \quad 1.5-1.92 .0-2.4 \quad 2.5-2.93 .0-3.4>3.5$

$$
-2000=-2003
$$

Enquête 2001 T1

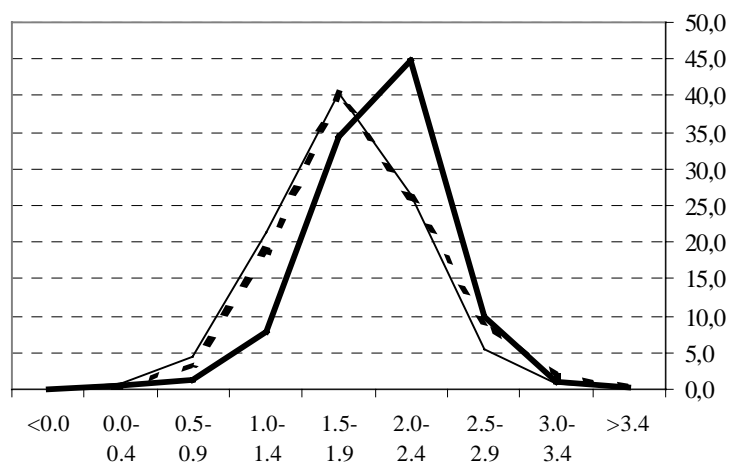

$$
2001-2002=-2005
$$

Survey in 2003q1

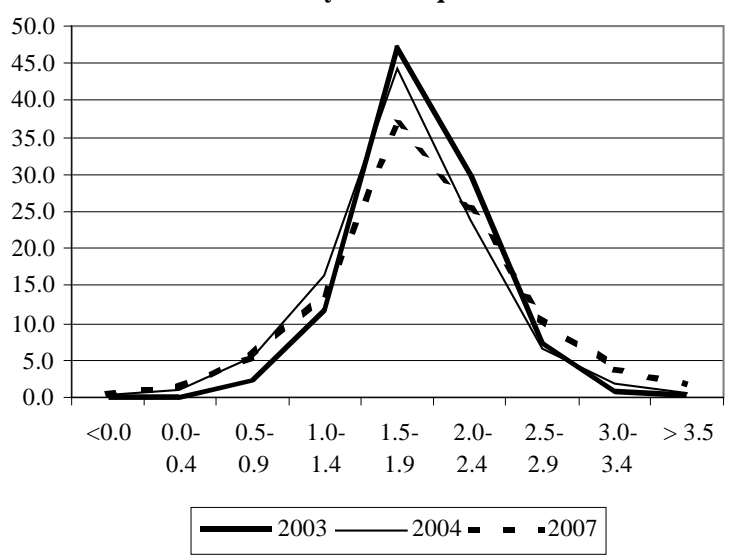

Survey in 2000q1

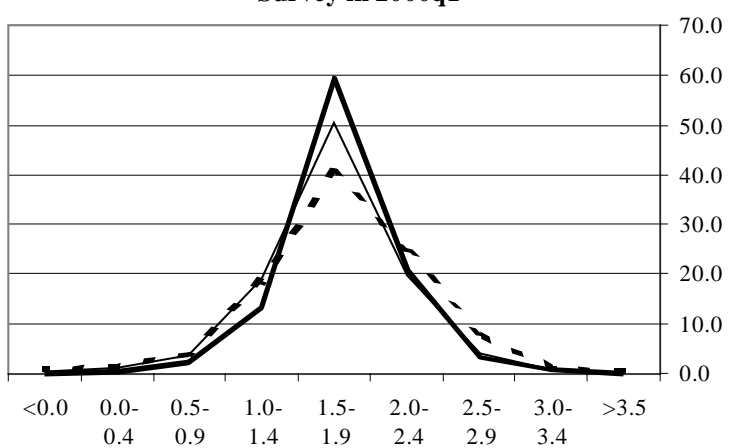

$-2000-2001--.2004$

Enquête 2002 T1

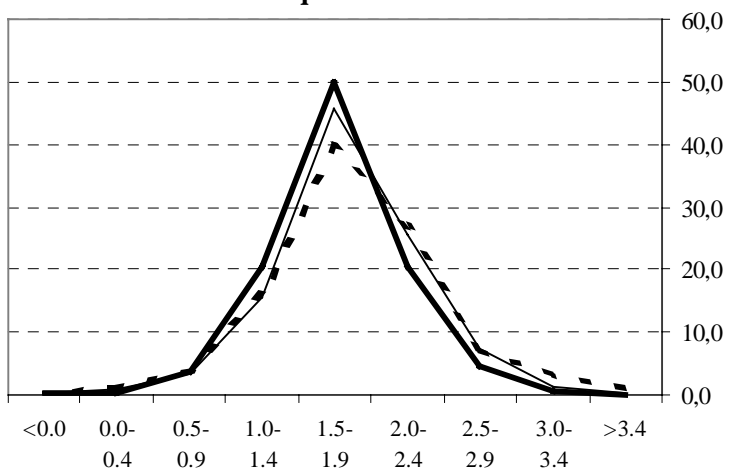

$2002-2003$ - - 2006

Survey 2003q2

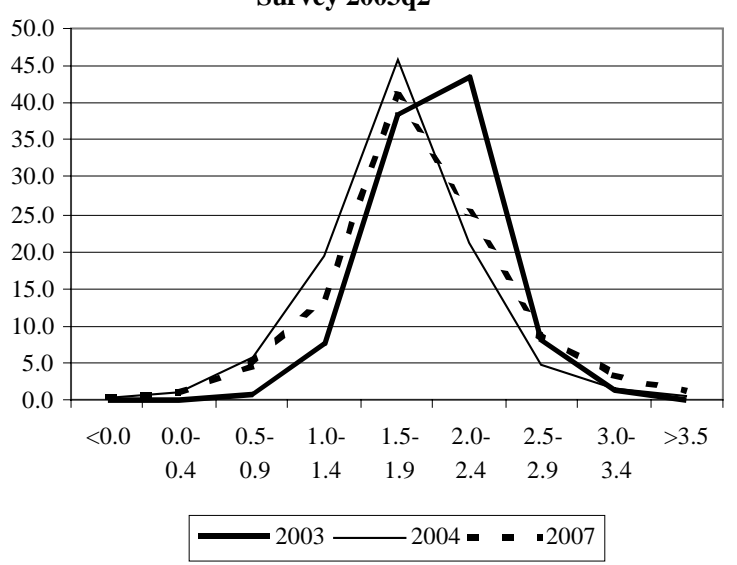

The low-inflation environment that the industrial countries' economies experienced in the 1990s was certainly a factor that helped to strengthen the solid anchoring of inflation expectations and it was not specific to the euro area. Table 1 below was drawn up from the results of the Consensus Forecast. It shows a substantial reduction in revisions of inflation expectations for the current year. The size of the reduction in the euro area is comparable to that observed in other countries and does not seem to be directly dependent on the strategic framework for monetary policy. 
Table 1:

Inflation expectations (percentage points)

\begin{tabular}{|c|c|}
\hline Mean variation of inflation expectations & Over current year (1) \\
\hline United States & 42 \\
$1990-2003$ & 32 \\
$1999-2003$ & \\
United Kingdom & 53 \\
$1990-2003$ & 22 \\
$1999-2003$ & \\
Canada & 64 \\
$1990-2003$ & 40 \\
$1999-2003$ & \\
\hline Euro area & 28 \\
\hline
\end{tabular}

Source: Consensus Economics - Banque de France estimates. The proxy for expected inflation in the euro area is the weighted mean of inflation expectations in Germany, France, Italy and the Netherlands from 1999 to2002.

\subsection{Short- and medium-term inflation determination and dynamics}

What influence has the ECB's monetary policy had on determining the equilibrium short-term price level? How does this policy influence inflation dynamics? New Keynesian theory provides the appropriate framework for answering these questions.

\subsubsection{Analytical framework}

Based on recent theoretical and applied research, we have chosen the following simplified model to represent the structure of the euro-area's economy and the monetary authorities' behaviour. ${ }^{14}$

(1) $\quad x_{t}=-\varphi\left(i_{t-1}-E_{t-1} \pi_{t}\right)+\theta x_{t-1}+(1-\theta) E_{t-1} x_{t+1}+g_{t}$

(2) $\pi_{t}=\lambda x_{t-1}+\phi \pi_{t-1}+(1-\phi) \beta E_{t} \pi_{t+1}+u_{t}$

(3) $i_{t}^{*}=\alpha+\gamma_{\pi}\left(E_{t} \pi_{t+2}-\pi^{*}\right)+\gamma_{x} x_{t}$

(4) $i_{t}=\rho i_{t-1}+(1-\rho) i_{t}^{*}$

(5) $x_{t} \equiv y_{t}-z_{t}$

(6) $\alpha=r^{*}+\pi *$

(7) $m_{t}-p_{t}=\kappa_{y} y_{t}-\kappa_{i} i_{t}+w_{t}$

where: $x$ is the output gap; $i$ is the nominal interest rate; $E_{t}$ is the conditional expectation calculated at date $\mathrm{t} ; \pi$ is the inflation rate; $g$ denotes a goods demand-side shock; $u$ denotes a supply-side shock; $p$ is the price level; $m$ denotes the money supply; $w$ denotes a money demand shock (all of the variables, except for the interest rate, are expressed as logarithms).

Equations (1) and (2) represent the structure of the economy. Equation (1) is an IS curve, where demand for goods and services depends negatively on the interest rate. Equation (2) is a Phillips curve, where inflation depends positively upon the output gap. The euro area's economy features persistence

\footnotetext{
${ }^{14}$ The choice of the model for the economic structure is based on Clarida, Gali and Gertler (1999), Ball (1997) and Svensson (1997). The model for the ECB's behaviour is based on Gali (2003).
} 
phenomena (see OECD, 2002, for example). Nominal rigidities hamper inflation adjustment during periods of slower economic activity. The rigidities stem from various origins: resistance to nominal wage reductions, owing to psychological factors (a form of the money illusion) and institutional factors (processes for renegotiating contracts); menu costs and the strategic behaviour of firms on markets with imperfect competition, leading them to wait until a competitor makes the first move before adjusting their prices, etc. To account for this situation, the output gap value in the $I S$ curve equation is lagged and the inflation value in the Phillips curve equation is lagged. Equation (7) represents equilibrium on the money market. In it, the demand for real balances depends on income and on the nominal short-term interest rate. This specification assumes that money-market securities are the only assets that can be substituted for money.

The adjustment lags in the economy mean that monetary policy affects inflation with a two-period lag. A change in the interest rate affects the output gap after one period and it then takes another period for the change in the output gap to affect prices. Equations (3) and (4) represent the central bank's behaviour. Equation (3) indicates the desired value of the nominal interest rate for the current period (i*). The first term represents the ECB's determination to anchor expectations at the value $\pi^{*}$. More specifically, the interest rate is raised or lowered according to the deviation from the target of the inflation rate forecast two periods ahead, since transmission lags make it impossible to affect inflation sooner. The output gap also influences $i^{*}$, even if price stability is the central bank's only objective. This is true because the structural characteristics of the economy incorporated into equations (1) and (2) mean that inflation in the current period is predetermined and responds to the output gap with a one-period lag (Rudebusch and Svensson, 1999; Gali, 2003). Furthermore, equation (4) introduces the possibility of inertia in the monetary authorities' behaviour, which leads to interest-rate smoothing.

Finally, the economy is affected by exogenous demand-side shocks $(g)$ and exogenous supply-side shocks $(u)$. It is simplest to assume that there is no correlation between shocks from one period to the next at this level. However, it would surely be more realistic to introduce persistence phenomena here too, for example by assuming that:

$$
\begin{aligned}
& g_{t}=\mu_{g} g_{t-1}+\hat{g}_{t} \\
& u_{t}=\rho u_{t-1}+\hat{u}_{t}
\end{aligned}
$$

\subsubsection{Inflation properties in relation to monetary policy}

In a steady state with no shocks $(g=u=0)$, the characteristics of the economy are as follows: the goods market is in equilibrium $(y=z)$ and the output gap is zero; the central bank's inflation objective has been achieved $\left(\pi=\pi^{*}\right)$ and the increase in wages is equal to productivity gains. To achieve this, the central bank's interest rate policy needs to comply with the Taylor principle: its response to a change in inflation expectations must be strong $\left(\gamma_{\pi}>1\right)$ because it has to adjust the real interest rate ex ante to stabilise the economy. A key property of the model is that the equilibrium value of the inflation rate is independent of the money supply. The latter is endogenous and automatically adjusts to the equilibrium values of national income and interest rates. As King (2002) noted, "if the model were an accurate description of the economy, the interest rate would be a sufficient statistic of monetary policy". Monitoring money supply growth does not provide any further information.

In the short term, the inflation rate may deviate from the central bank's target in the event of temporary supply-side shocks, such as changes in productivity gains or energy and commodity prices, or in response to demand-side shocks, such as fiscal policy decisions. The following equation describes inflation dynamics: 


$$
\pi_{t}=a_{0}+a_{\pi} \pi_{t-1}+a_{u} u_{t}
$$

With :

$$
\text { avec: } 0 \leq a_{\pi} \leq 1 \quad \text { et } \quad \pi^{*}=\frac{a_{0}}{1-a_{\pi}}
$$

The persistence of inflation (as measured by $a_{\pi}$ ) depends on shocks and the previously observed structural characteristics of both the demand and supply sides. It also depends on the monetary authorities' behaviour. Reversion to the inflation target $\pi^{*}$ takes place more quickly if: a) the monetary authorities' reaction to changes in inflation expectations (as measured by $\gamma_{\pi}$ ) is strong and b) interestrate smoothing (as measured by $\rho$ ) is weak.

The variability of inflation is directly linked to the size of supply-side shocks, since monetary policy is able to neutralise the effects of demand-side shocks: ${ }^{15}$

$$
\sigma_{\pi}=\frac{a_{u}}{1-a_{\pi}} \sigma_{u}
$$

If this representation is correct, "once a situation is reached with a widespread expectation that monetary policy is able and willing to generate a low inflation rate, all future-oriented nominal contracts are based on a low inflation component so that future wage and price increases will in fact be low. It is obvious that this mechanism has a self-stabilising tendency. If the public is convinced of having a stability-oriented central bank, temporary deviations of the inflation rate are not regarded as a sign of incompetence or a deliberate inflation policy. Thus, expectations remain unchanged, which allows to regain the original low inflation rate" (Bofinger, 2000a).

In practice though, things are much more complicated and anchoring inflation expectations carries some risks. These arise from the problems encountered in determining whether shocks are temporary or permanent. For example, a demand-side shock in a situation where the central bank enjoys strong credibility could give rise to tension on the labour market without triggering an increase in inflation. Wage-earners will not ask for an increase in nominal wages because they are convinced that firms will not raise their prices. Meanwhile, firms are encouraged not to change their prices, even if wage costs increase, and we see a decline in the inflation rate accompanied by a decline in the pricing power of firms (Taylor, 2000). Both firms and wage-earners think that the excess demand will be temporary and that it will be eliminated by an increase in interest rates. But the anchoring of expectations may lead the bank to delay raising its interest rates. Similarly, in the event of a favourable supply-side shock, in a situation where the central bank enjoys good credibility and expectations are solidly anchored, both the private sector and the central bank may underestimate the potential output level. Once again, there is a risk that interest rates will not be raised far enough and the threat of an unsustainable boom in the economy in general, and in asset markets in particular, that will be followed by a period of painful adjustment. This is what happened in the United States between 1996 and 1999. The central bank becomes a victim of its own credibility and the subsequent anchoring of expectations (Goodfriend, 2001, 2002). The danger is more acute because the indicators that the authorities use to guide their action may become less reliable during such periods (Orphanides, 2001). The error lies in believing that the economic agents' behaviour (wage-earners' pay demands and firms' price-setting) is independent from the inflation environment. This behaviour changes once the private sector no longer believes that the central bank is determined to raise its rates to keep inflation low. For example, in the event of a demand-side boom, firms' profit margins may stay abnormally low, until firms lose confidence in the central bank's determination not to accommodate inflation (Taylor, 2000).

\footnotetext{
${ }^{15}$ If we assume that the central bank has all of the information necessary to identify such shocks when they occur.
} 


\subsection{Monetary policy and inflation in the euro area}

The theoretical framework presented above is used to analyse short- to medium-term developments in the inflation rate in the euro area by looking at its various characteristics (level, variability, persistence) in turn. It is also used to analyse the contribution that monetary policy makes in this area.

\subsubsection{Method used for empirical analysis}

Theoretical analysis shows that the equilibrium inflation rate and its dynamic properties result from interactions between shocks to the economy, the structural characteristics of the economy and the monetary authorities' behaviour. It would take an analysis using a full model of the euro-area economy to isolate the different influences affecting prices and, more particularly, the influence of the ECB's action. The method used here is a more succinct one. The experience of the euro area is examined on the basis of estimates from two equations: the equation that explains price dynamics, and the one that reflects the central bank's reaction function. This method, which Adolfson and Söderstrom (2003) and Crawford (2001) use to analyse the impact of an inflation targeting regime on short- to medium-term inflation dynamics in Sweden and Canada, is acceptable and leads to accurate conclusions if we ensure that the error terms in the estimated equation have the right statistical properties in every case, meaning no correlation and normality and stability of variance.

\subsubsection{Inflation variability}

Inflation variability is analysed using equation (10). The theoretical model "acknowledges the existence of short-term volatility in prices, resulting from non-monetary shocks to the price level that cannot be controlled by monetary policy "(ECB, 1999a, p. 47). Chart 6 shows the distribution of variation rates for the HICP from 1993q1 to 2003q3. Chart 7 shows the distribution of variation rates for core inflation. Both charts once again show the effect of temporary shocks, particularly when we look at the relatively high frequency of price deviations at both extremities of the distributions. Paradoxically, however, the total inflation variation rates are more strongly clustered around a mean value close to $2.2 \%$ than the core inflation variation rates are. The latter appear to be more volatile over the whole period. The holds true when the sample is restricted to the period from 1999 to 2003. In this case the mean for the HICP is close to $2 \%$ with a standard deviation of about $0.56 \%$, whereas the mean for core inflation is $1.7 \%$ with a standard deviation of $0.64 \%$.

\section{Chart 6 \\ Distribution of year-on-year variations in the HICP}

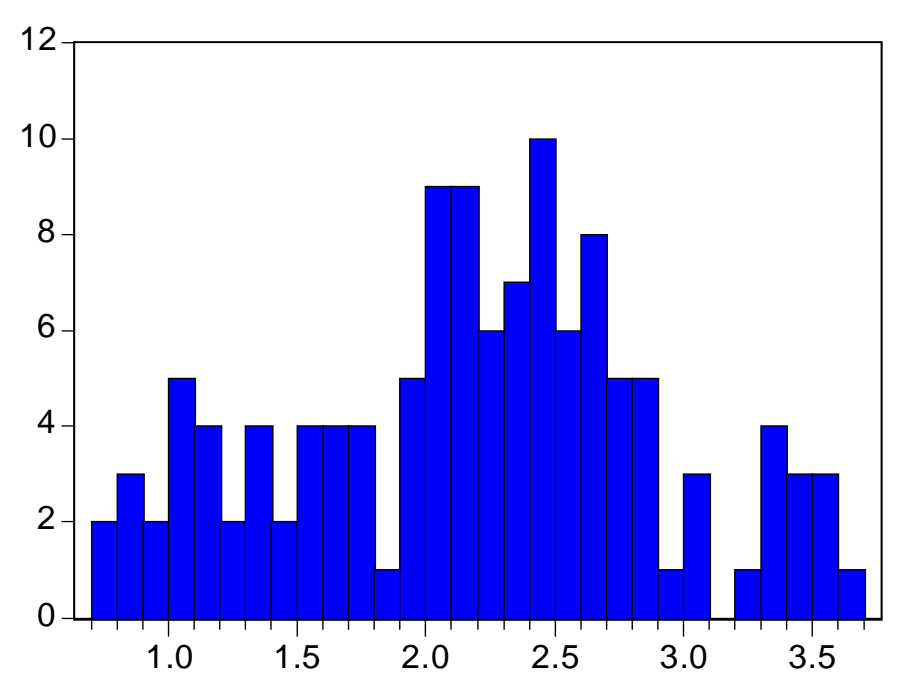

Series: Glissement annuel de l'IPCH Période 1993:01 2003:03

Observations 123

Mean

2.183826

Median

2.242991

Maximum

3.628118

Minimum $\quad 0.781250$

Std. Dev. $\quad 0.705832$

Skewness $\quad-0.076798$

Kurtosis $\quad 2.397745$

Jarque-Bera 1.979801

Probability $\quad 0.371614$ 


\section{Chart 7}

\section{Distribution of year-on-year variations in the core inflation rate ${ }^{16}$}

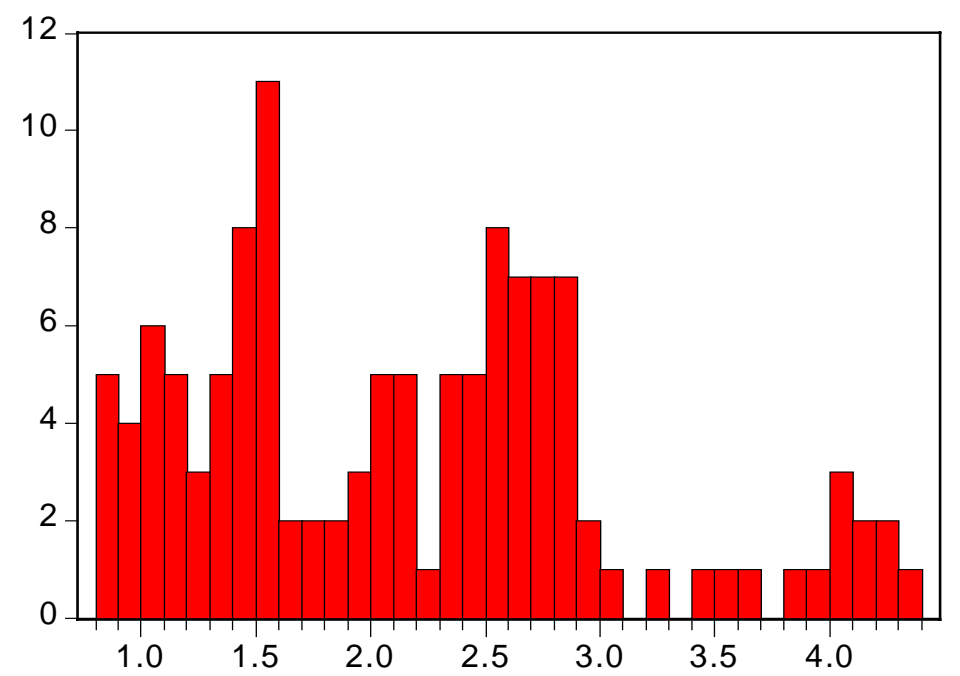

Series : Inflation sous-jacente

Période : 1993:01 2003:03

Observations 123

Mean

2.154860

Median

2.102377

Maximum

4.342857

Minimum

0.862069

Std. Dev.

0.893111

Skewness

0.595533

Kurtosis

2.720784

Jarque-Bera 7.670076

Probability $\quad 0.021601$

Hereafter, we shall focus on developments in the HICP, which is the measure that the ECB uses.

\subsubsection{Inflation rate persistence and autocorrelation}

Inflation rate autocorrelation depends on the monetary authorities' behaviour (equation (10)) For example, if the authorities keep the inflation rate to the median of a target range one and a half to two years ahead, the shocks affecting the current value of the inflation rate will be inverted over this period. There will be no correlation between current inflation and the inflation rate at the time horizon in question. If this time horizon is more distant, for example two years ahead, the first autocorrelation coefficient may be positive. In this case the confidence interval defined for the inflation rate will diminish over time.

On the other hand, if the monetary authorities are not committed to a price stability objective, an increase in current inflation tends to be persistent and there is a positive correlation between current and future inflation. In this case, the confidence interval increases and there is more uncertainty about future inflation.

One simple way to assess the autocorrelation of inflation rates is to estimate equation (9) using monthly data. In order to consider monthly results, we look at the relationship between the current inflation rate over twelve months and past inflation rates over twelve-month periods that do not overlap (see Crawford, 2001, for example):

$$
\pi_{t}=a_{0}+\phi_{1} \cdot \pi_{t-12}+\phi_{2} \cdot \pi_{t-24}+\varepsilon_{t}
$$

The results are shown in Table 2. The estimated values of the parameters relating to lagged inflation are significantly different from zero. More specifically, the first autocorrelation coefficient, measured one year ahead, is positive, while the second, measured two years ahead, is negative. This pattern corresponds to a situation where the ECB is trying to bring the inflation rate back in line with its target within two years. This objective can be estimated by rewriting the equation as follows:

\footnotetext{
${ }^{16} \mathrm{HICP}$ except for energy and unprocessed food.
} 


$$
\pi_{t}=\left(1-\phi_{1}-\phi_{2}\right) \pi^{*}+\phi_{1} \cdot \pi_{t-12}+\phi_{2} \cdot \pi_{t-24}+\varepsilon_{t}
$$

where $\pi^{*}$ is the steady-state inflation rate, which can also be seen as the medium-term inflation target.

Its estimated value, ${ }^{17}$ in view of the results shown in Table 2, is equal to $1.94 \% .18$ This is in line with the ECB's announcement that it would maintain the inflation rate close to, but below, $2 \%$.

\section{Table 2}

Dependent variable: $\pi$

\begin{tabular}{|c|c|c|c|c|}
\hline \multicolumn{5}{|c|}{ Dependent variable: $\pi$} \\
\hline Variable & Coefficient & Std. Error & t-Statistic & Prob. \\
\hline$\pi_{\mathrm{t}-12}$ & 0.679282 & 0.098028 & 6.929496 & 0.0000 \\
\hline$\pi_{\tau-24}$ & -0.257614 & 0.080719 & -3.191476 & 0.0019 \\
\hline $\mathrm{C}$ & 0.011270 & 0.001627 & 6.926164 & 0.0000 \\
\hline R-squared & 0.348351 & Mean de & ent var & 0.019550 \\
\hline Adjusted R-squared & 0.334775 & S.D. $\mathrm{de}_{\mathrm{I}}$ & nt var & 0.005681 \\
\hline S.E. of regression & 0.004634 & Akaike i & iterion & -7.881039 \\
\hline Sum squared resid & 0.002061 & Schwar & erion & -7.802399 \\
\hline Log likelihood & 393.1114 & & & 25.65932 \\
\hline Durbin-Watson stat & 0.359047 & $\operatorname{Prob}(\mathrm{H}$ & stic) & 0.000000 \\
\hline
\end{tabular}

Empirical studies on a number of countries show that persistence varies over time depending on the nature of monetary policy. ${ }^{19}$ What does observation of the euro area show? Have the creation of the ECB and the implementation of its price-stability-oriented monetary policy strategy had an impact on the autocorrelation of inflation rates? A comparison between the period from 1993 to 1998 and the period from 1999 to 2003 can provide some helpful information on the subject, even though there are obvious limitations. It would be simplistic to attribute all changes to the new monetary regime, since other factors, such as the change in exogenous shocks affecting inflation, could be involved too. Other factors might include economic agents' anticipation of the regime change long before it came into effect. Chart 8, which plots the autocorrelation of inflation rates over each of the two periods, shows two changes. Overall, persistence seems to have diminished. The autocorrelation coefficient is weaker with each successive lag. The autocorrelation coefficient has become negative in the recent period for lags of one and a half years up to two years. This confirms an earlier observation and its interpretation as showing the ECB's determination to bring the inflation rate back in line with its target within two years.

\footnotetext{
${ }^{17} \pi^{*}$, the steady-state inflation rate is derived from: $\pi^{*}=\frac{C}{1-\varphi_{1}-\varphi_{2}}$

${ }^{18}$ In view of the margin of error on the constant alone, the 95\% confidence interval is [1.4\% to $2.5 \%$ ].

${ }^{19}$ For example, Longworth (2002) shows that the dynamic behaviour of Canadian inflation underwent fundamental changes after the inflation target was adopted in 1991. One of the main changes was the decline in the autocorrelation of inflation rates.
} 


\section{Chart 8}

Autocorrelation (year-on-year change in euro area HICP)

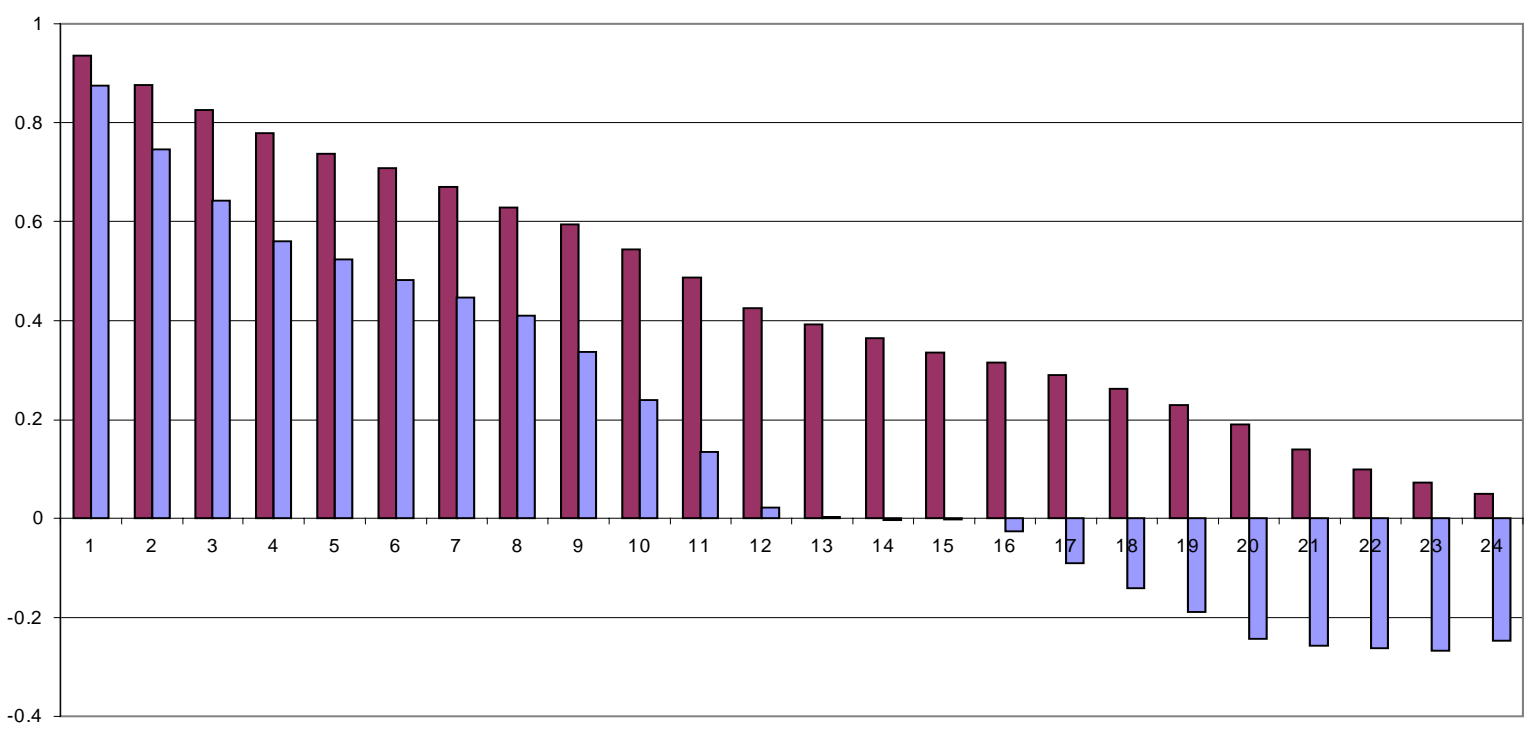

ロ1993-1998 ㅁ1999-2003

In order to make sure that this result is meaningful, we compare the value of the coefficients for successive lagged inflation rates over two sub periods (Chart 9) and the 95\% confidence intervals around the estimated values of these coefficients (Chart 10).

Chart 9

\section{Coefficients estimated by linear regression (current inflation over past inflation)}

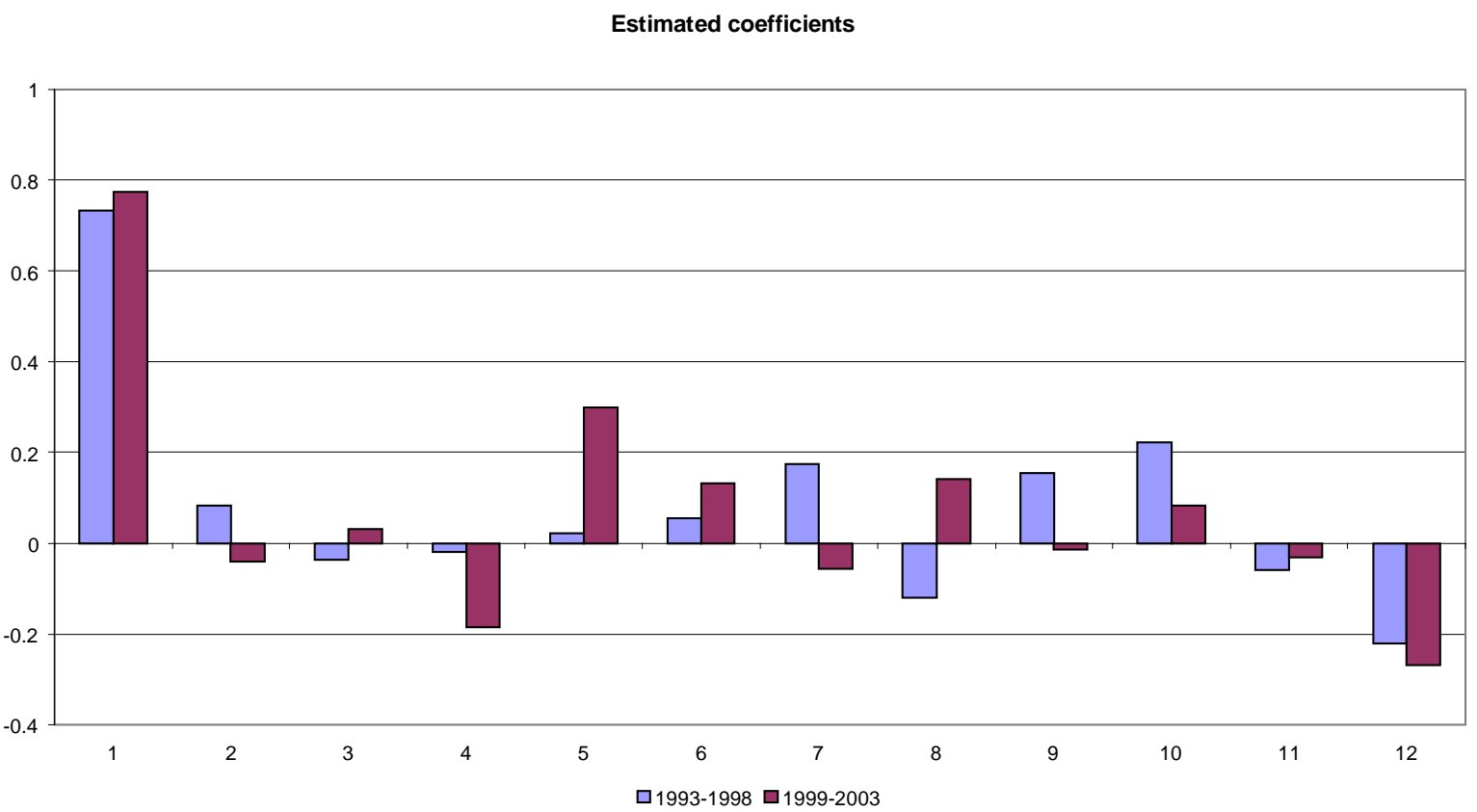


Chart 10

\section{Confidence intervals around the coefficients}

$95 \%$ confidence intervals

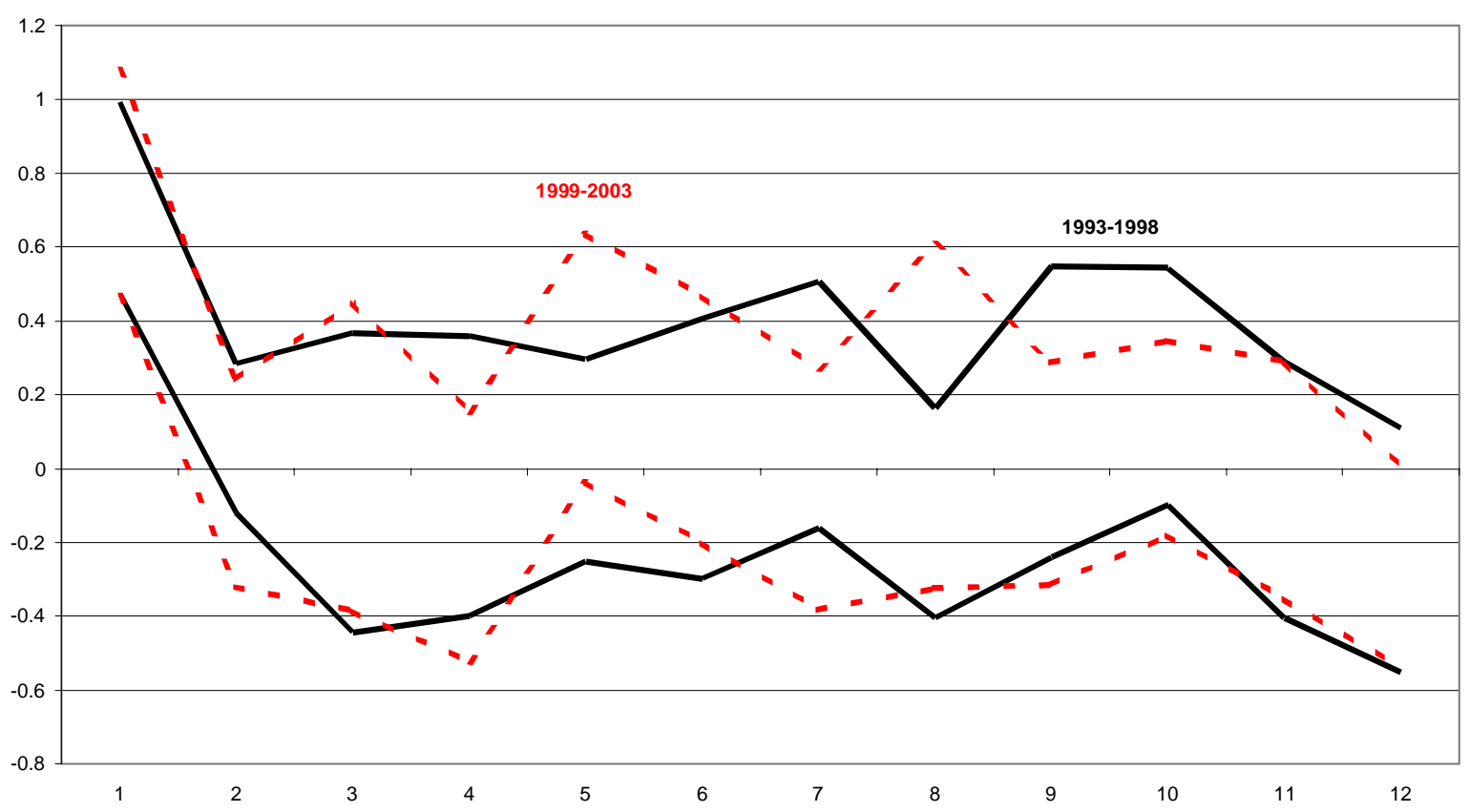

These two charts show that it is very difficult to distinguish between the two sub-periods at the statistical level. With a few rare exceptions, the value of the coefficient hardly changes from one period to the next and the $95 \%$ confidence intervals are practically indistinguishable. Furthermore, these coefficients are not statistically different from zero.

\subsubsection{Short-term price-level uncertainty}

Uncertainty about short-term inflation can first be measured by the conditional variance of forecasting errors derived from a generalised autoregressive conditional heteroscedastisity model of inflation ${ }^{20}$ (Crawford and Kasumovich, 1996; Jenkins and O'Reilly, 2001; Longworth, 2002). Such a measure constructed for the euro area on the basis of a GARCH(1.1) model estimated for the period from 1993 to 2003 produces the following results:

\section{Chart 11}

\section{Uncertainty about inflation (HICP)}

(conditional variance)

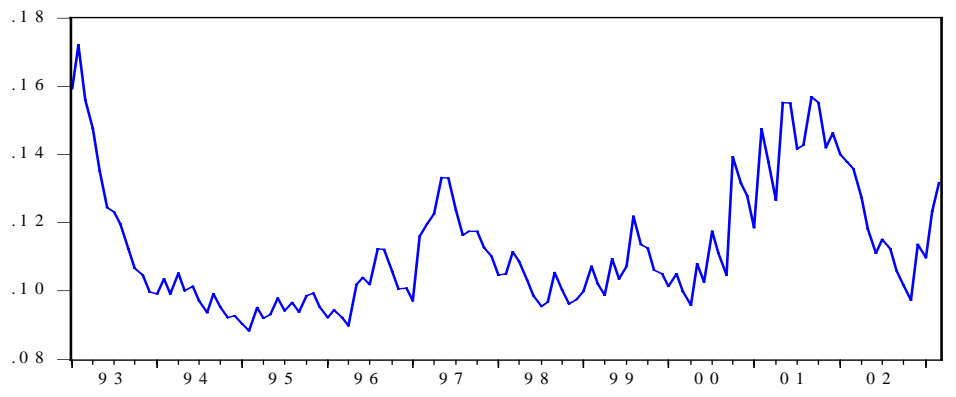

\footnotetext{
${ }^{20}$ In this type of model, the expected variance of inflation for the following period, which is also called conditional variance, is assumed to depend on three terms: mean inflation, new information about volatility obtained during the previous period and measured as the square of the forecasting error, and past variance forecasts.
} 
Uncertainty about inflation during the period under review seems to stabilise at low levels at the end of the nineteen-nineties. It then increases rapidly, concomitantly with energy price shocks and unprocessed food price shocks, and again with the changeover to the euro. At the very end of the period, when uncertainty seems to ease and return to its earlier levels, the rise in oil prices brings with it a fresh surge in uncertainty. The estimation of the GARCH model also shows how highly entrenched the impact of shocks on inflation volatility is, as the autoregressive root corresponding to the sum of the coefficients on the ARCH and GARCH terms is close to unity $(0.88)$.

We can use a second type of indicator, which is based on the dispersion of inflation forecasts according to the time horizon for the forecast. Chart 12 below shows this indicator, which is derived from the ECB's Survey of Professional Forecasters mentioned above. As we can see in Chart 12, the dispersion naturally tends to increase as the time horizon grows more distant. The variance of forecasts four years ahead $(\mathrm{n}+4)$, two years ahead (or eight quarters, denoted $q+8$ ) and one year ahead is generally greater than the variance of forecasts relating to the current year is. However, there is a steady diminishing trend in the dispersion of inflation forecasts four years ahead, which could be interpreted as a sign of reduced uncertainty about the short- to medium-term inflation rate. This trend corroborates the conclusions drawn on the basis of the preceding indicator to a certain extent.

\section{Chart 12}

ECB Surveys of Professional Forecasters: standard deviation

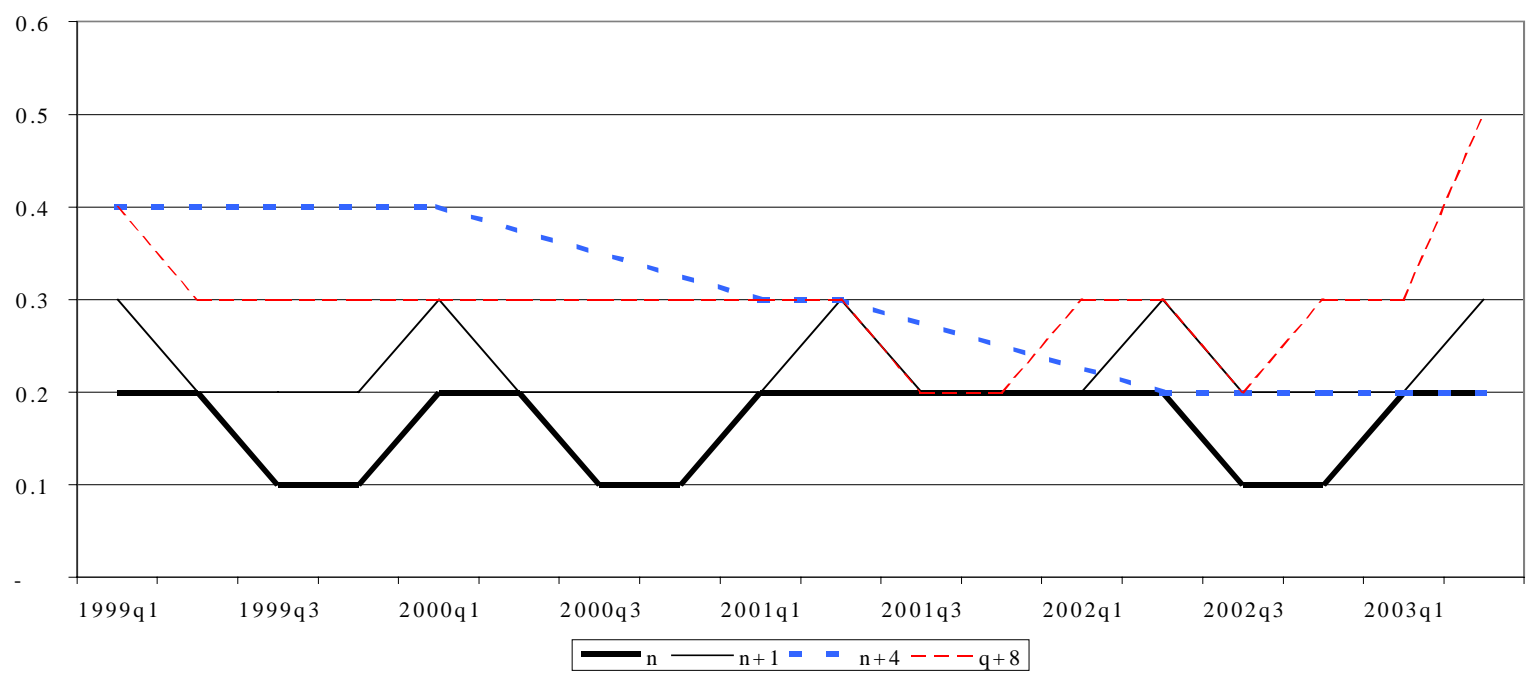

\subsubsection{Information provided by money}

Even though the New Keynesian analytical framework seems to attribute it a limited role, money can still be useful for monetary decision-making because of its information content with regard to future activity and inflation.

Tables 3 and 4 below show some empirical results obtained from an analysis based on the approach originally proposed by Stock and Watson (2001), where the predictive powers of some fifty potential leading indicators are assessed with regard to future activity and inflation in the euro area. The indicators assessed include certain commodity prices, a vast assortment of asset prices and financial variables, a measure of the output gap and, finally, monetary aggregates. The estimates are made for the period from 1980 to 2002 . The quality of a leading indicator is measured on the basis of its predictive powers two, four and eight quarters ahead. The tables show the Relative Root Mean Square Error (Relative RMSE) of the forecasts made without samples and obtained with the help of a purely autoregressive model of activity growth and inflation and those obtained using a model that incorporates current and past values of the leading indicator under consideration. A ratio of less than 1 shows that the indicator contains information about future activity or inflation, since taking it into 
account helps to improve forecasting of the variable in question. Of the fifty or so indicators tested, only those possessing this property were selected. In addition, the tables show the time horizon at which the best forecast of each indicator is obtained. For example, in Table 3 below, including the three-month interest rate helps achieve a 10\% improvement (Relative RMSE equals 0.90) in the activity growth forecast obtained with a purely autoregressive model at a time horizon of four quarters. The figures in parentheses are the results of the test proposed by Diebold and Mariano (1994), which measures whether the forecast obtained using the potential leading indicator is statistically different from the forecast derived from the purely autoregressive mode ${ }^{21}$. A high probability value means that it is difficult to distinguish between the two forecasts statistically. Only the leading indicators with the strongest predictive powers are included in the table.

Starting with the results obtained from Table 3, we see that the monetary aggregate M2 expressed in real terms has the best predictive powers of any of the potential leading indicators studied at a oneyear time horizon, with M1 (expressed in real terms as well) coming a close second.

The information content of these monetary aggregates with regard to activity growth largely exceeds the information content of asset prices and other financial variables selected for this study.

$\underline{\text { Table } 3}$

Best leading indicators for activity growth in the euro area

\begin{tabular}{|l|cc|c|}
\hline Leading indicator & Relative RMSE & $($ p-values $)$ & Horizon (quarters) \\
\hline Three-month interest rate & 0.90 & $(0.38)$ & 4 \\
\hline Two-year yield on govt. securities & 0.95 & $(0.60)$ & 4 \\
\hline Spread (10 years - three months) & 0.99 & $(0.99)$ & 2 \\
\hline Commodity prices & 0.99 & $(0.88)$ & 2 \\
\hline Real market capitalisation & 0.96 & $(0.29)$ & 8 \\
\hline Real equity prices & 0.99 & $(0.87)$ & 8 \\
\hline Detrended three-month rate & 0.92 & $(0.42)$ & 8 \\
\hline Real gold price & 0.98 & $(0.89)$ & 2 \\
\hline Real M1 & 0.92 & $(0.54)$ & 4 \\
\hline Real M2 & 0.86 & $(0.17)$ & 4 \\
\hline
\end{tabular}

Source: Clerc (2002)

These two monetary aggregates also have good predictive powers with regard to inflation, but to a lesser extent. However, their information content seems to relate to longer time horizons, of eight quarters in this case. Furthermore, they are dominated by asset prices or financial variables and oil prices.

Table 4

\section{Best leading indicators for inflation in the euro area}

\begin{tabular}{|l|cc|c|}
\hline Leading indicator & Relative RMSE & $($ p-values $)$ & Horizon (quarters) \\
\hline Two-year yield on govt. securities & 0.89 & $(0.58)$ & 8 \\
\hline Five-year yield on govt. securities & 0.96 & $(0.58)$ & 8 \\
\hline Gold price (nominal) & 0.98 & $(0.74)$ & 4 \\
\hline Real gold price & 0.87 & $(0.46)$ & 8 \\
\hline Real oil price & 0.87 & $(0.17)$ & 4 \\
\hline Real M1 & 0.90 & $(0.76)$ & 8 \\
\hline Real M2 & 0.96 & $(0.89)$ & 8 \\
\hline
\end{tabular}

Source: Clerc (2002)

\footnotetext{
${ }^{21}$ The autoregressive model for inflation performs reasonably well over the sample period. This result contrasts with Bruneau et al. (2003) who found that a "Phillips curve" like model is a better performer after 1999. However, according to our own findings, the output gap, as measured by the deviation of the log of real GDP from a one-sided HP filter, does not improve the inflation forecasts.
} 
The M3 monetary aggregate, which belongs to the set of our potential leading indicators, does not seem to have particularly notable information content about either future activity growth or inflation for time horizons of less than two years. However, the scale of portfolio shifts seen in the euro area, particularly massive acquisitions of money market fund units in a context of stock market volatility, has undoubtedly accounted for some weakening of this information content.

\subsubsection{Compliance with the Taylor principle and the limitations of short- to medium-term analysis}

The "Taylor principle" is the condition that is theoretically necessary to ensure economic stability. Does it hold empirically for the euro area? The ECB's interest rate policy has given rise to concern, or questions in this regard. Gali (2003) compared the observed interest rate values from January 1999 to April 2002 to the reference values calculated using a modified version of equation (3):

$$
i_{t}^{*}=\alpha+\pi^{*}+\gamma_{\pi}\left(\pi_{t}-\pi^{*}\right)+\gamma_{x} x_{t}
$$

with $\gamma_{\pi}=1.5, \mathrm{r}^{*}=2.5, \pi *=1.5$ and assuming that there is no interest-rate smoothing $(\rho=0)$. It appears that, "with the exception of the very early part of the sample, the interest rate set by the ECB has remained substantially below the level implied by the benchmark rule". Artus (2002a) confirmed this conclusion with an estimate made on virtually the same period (January 1999 to March 2002) using equation (3'). This produced the following results:

$$
\begin{aligned}
i_{t}= & -26,4+0,65 \pi_{t}+0,35 x_{t} ; R^{2}=0,87 ; D W=0,49 \\
& (6,4) \quad(7,6) \quad(6,8) \\
i_{t}= & -11,7+0,16 \pi_{t}+0,15 x_{t}+0,70 i_{t-1} ; \quad R^{2}=0,98 ; D W=1,71 \\
& (6,0) \quad(3,3) \quad(6,1) \quad(14,0)
\end{aligned}
$$

(Student's T)

This shows that the interest rate was set too low with regard to inflation $\left(\gamma_{\pi}<1\right)$. These results would suggest that the ECB is unresponsive to inflation developments, since the short-term interest rate is too low with regard to inflation. If this were so, there would be every reason to be concerned. For example, Artus concludes that if this characteristic were true, the equilibrium inflation rate in the euro area would be greater than $2.5 \%$, which was its value at the time he conducted his study. ${ }^{22}$

Analysis of the ECB's interest rate policy must not, in fact, be based on the actual inflation rate, as it is in equation (3'), but on its expected value, as it is in equation (3). Gali (2003) shows that, in this case, the observed values of the interest rate are closer to the reference values (Chart 13). But some episodes are still hard to explain, according to Gali. There was no tightening of monetary policy after May 1999, even though a significant increase in the expected inflation rate was observed. The increase in inflation expectations in early 1999 was an international phenomenon that did not elicit a rapid response from the central banks concerned. ${ }^{23}$ Then, there was a series of interest rate hikes starting in November 1999, even though there was no notable change in the expected inflation rate.

\footnotetext{
${ }^{22}$ Nevertheless, these equations produce astonishing results. More specifically, according to equation (3'), the constant of the regression corresponds to the expression $\alpha+\left(1-\gamma_{\pi}\right) \pi^{*}$, where $\alpha$ corresponds to the real interest rate. In view of the small estimated value of $\gamma_{\pi}$, the large negative value of the constant implies a very negative real interest rate in the euro area!

23 This episode is discussed further in 3.1.
} 


\section{Chart 13}

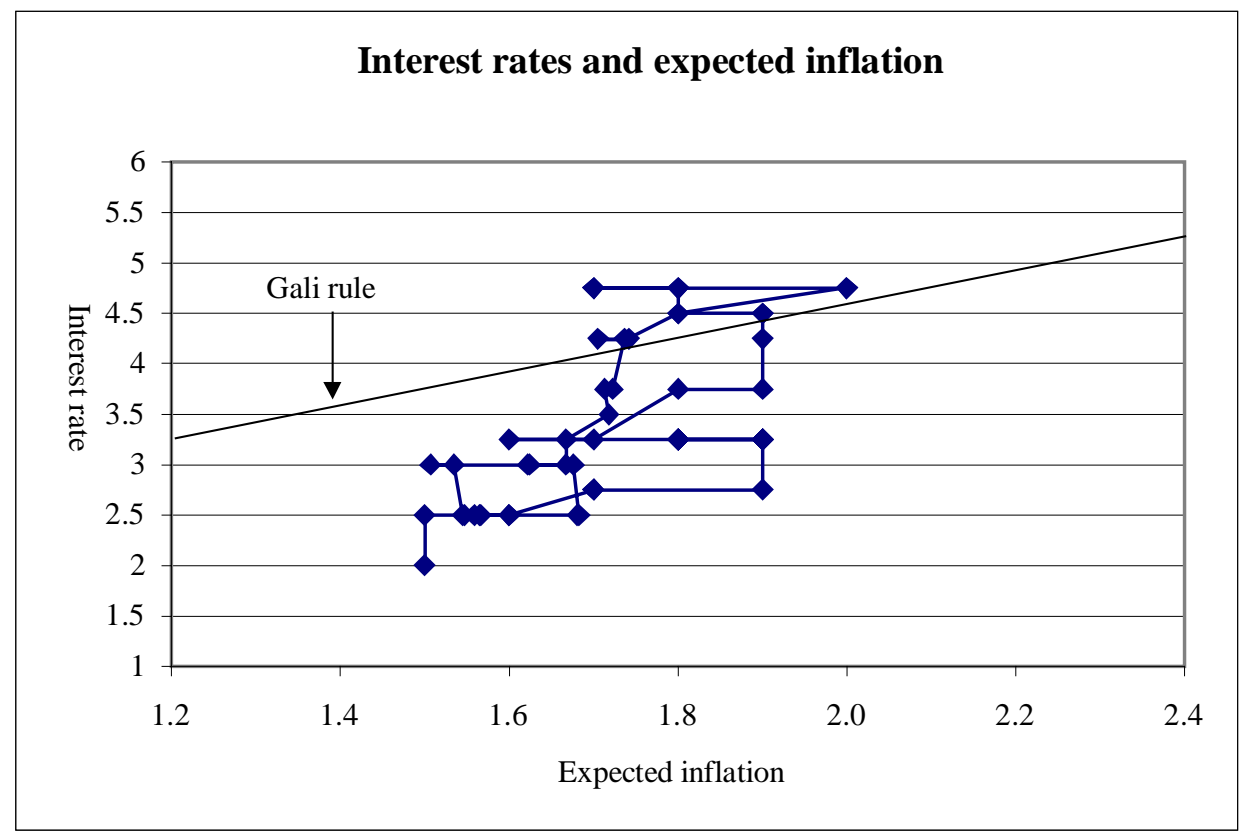

However, in Chart 12, the straight line of best fit through the cluster of points, meaning the straight line of the regression between interest rates and expected inflation, would have a slope equal to 3 , suggesting that the ECB's official interest rates react strongly to expected inflation one year ahead.

Contrary to what this suggests, non-compliance with the Taylor principle is also shown by another estimation of equation (3') for the period from January 1999 to April 2002. The estimation is another one from Artus (2002) and is contained in his report to the Council for Economic Analysis:24

$i_{i}=-13,7+0,06 E_{t} \pi_{t+1}+0,17 x_{t}+0,76 i_{t-1} ; R^{2}=0,98 ; D W=1,73$
$(5,2) \quad(1,8)$
$(5,3)$
$(11,2)$

avec $i_{t}$ taux repo et $E_{t} \pi_{t+1}$ inflation prévue consensus

This result may be explained by the extreme simplicity of the methods that the authors cited used to estimate the value of $\gamma_{\pi}$ and by econometric problems. For example, the paucity of observations available since the ECB started conducting monetary policy makes estimation of its reaction function an extremely delicate exercise ${ }^{25}$. But, at a more fundamental level, we should discuss the limitations of the type of theoretical modelling used up until now. This is shown very clearly in some theoretical research where some hypotheses are borne out and it is demonstrated that compliance with the Taylor principle alone is not enough to ensure the uniqueness and equilibrium of rational expectations. First of all the government's budget constraint must not be overlooked. Compliance with the Taylor principle in a situation where the fiscal authorities are non-Ricardian, meaning that they do not take account of this constraint ex ante, may lead to an explosive rise in the price level. In the event of an inflation shock, an increase in the real interest rate by the central bank would lead to an increase in the

\footnotetext{
24 This estimation, like the previous ones, implies a negative real interest rate for the euro area.

${ }^{25}$ For instance, Gesdesmeier and Roffia (2003) estimated similar relations but mainly on the pre-EMU period (1985-2001), using the GMM. They found that the Taylor principle was generally satisfied, using different specifications. However, the very high values of the coefficient of their lagged interest rate, generally above 0.95 , as well as those of the $\mathrm{R}^{2}$ statistics, close to 0.99 , might suggest the presence of units roots and therefore should lead to a cautious interpretation of their results.
} 
interest expense on the public debt, which would trigger a further increase in inflation. The central bank would respond with another rate increase and the cycle would continue (Asselain et al, 2002; Leeper, 1991, Loyo, 1999). In such a situation, it is better for the value of $\gamma_{\pi}$ to be less than unity. The same holds true if we take account of the liquidity constraints that economic agents have to cope with (Masuch et al. 2003). Theses results illustrate a more general conclusion: if monetary policy is to ensure monetary stability, then it must not concern itself solely with anchoring short- to medium-term expectations; it must also be concerned with medium- to long-term anchoring of expectations.

\section{Anchoring inflation expectations and price-level stability in the medium to long term}

The ECB's strategy now needs to be analysed in the medium to long term. This is defined as a period ranging from the average length of a business cycle (a few years) up to the time horizon for economic agents' intertemporal decision-making (twenty to thirty years). Analysis is necessarily a delicate matter at the empirical level, since there are only a few years of experience on which to base a calculation of the steady-state inflation rate for the euro area. The theoretical model needs to be supplemented to account explicitly for the role that the ECB attributes to money in anchoring longterm inflation expectations. Interpreting developments observed within the framework defined should make it possible to evaluate the contribution that monetary policy makes to long-term price stability in the euro area.

\subsection{Steady-state inflation and anchoring medium- to long-term expectations}

We have seen that temporary shocks have dominated short-term inflation dynamics in the euro area since 1999 without undermining the stability of short-term inflation expectations. What is the situation with regard to the economy's steady state? What is the value of the equilibrium inflation rate? Are long-term inflation expectations as stable as the short-term expectations are?

\subsubsection{Stability of the medium-term inflation rate}

Price-level uncertainty tends to diminish more than one year ahead if monetary policy always attempts to steer inflation towards a quantified final target. The mean inflation rate over $n$ years is given by:

$\bar{\pi}_{(n)}=\sum_{i=1}^{n} \pi_{i} / n$ where $\pi_{i}$ corresponds to the inflation rate for a given year.

When inflation rates are not correlated from one year to the next, the standard deviation of the mean annual inflation rate calculated over $n$ years is given by:

$\sigma_{\bar{\pi}}=\sigma / \sqrt{n}$ where $\sigma$ represents the standard deviation of the inflation rate over 12 months.

The standard deviation of mean inflation, therefore, is inversely proportional to the number of years $n$ considered when calculating the mean. Chart 14 shows the construction of a confidence interval for the successive year-on-year changes in the HICP for the euro area calculated from January 1992. It is assumed that the monetary authorities are aiming at a target close to $2 \%$ and that the bounds of the target range were set at one point either side of the target in January 1992.

As the chart below shows, the mean inflation rate does not fall within the confidence interval until the very end of the nineteen-nineties and it then stabilises at a level close to $2.5 \%$. However, the convergence process undoubtedly affects the period under review and the price dynamics cannot be considered to be illustrative of the single monetary policy. Furthermore, euro area inflation was correlated over this period, as the estimates presented in Table 2 show. 
Chart 14

Year-on-year change since January 1992 (\%)

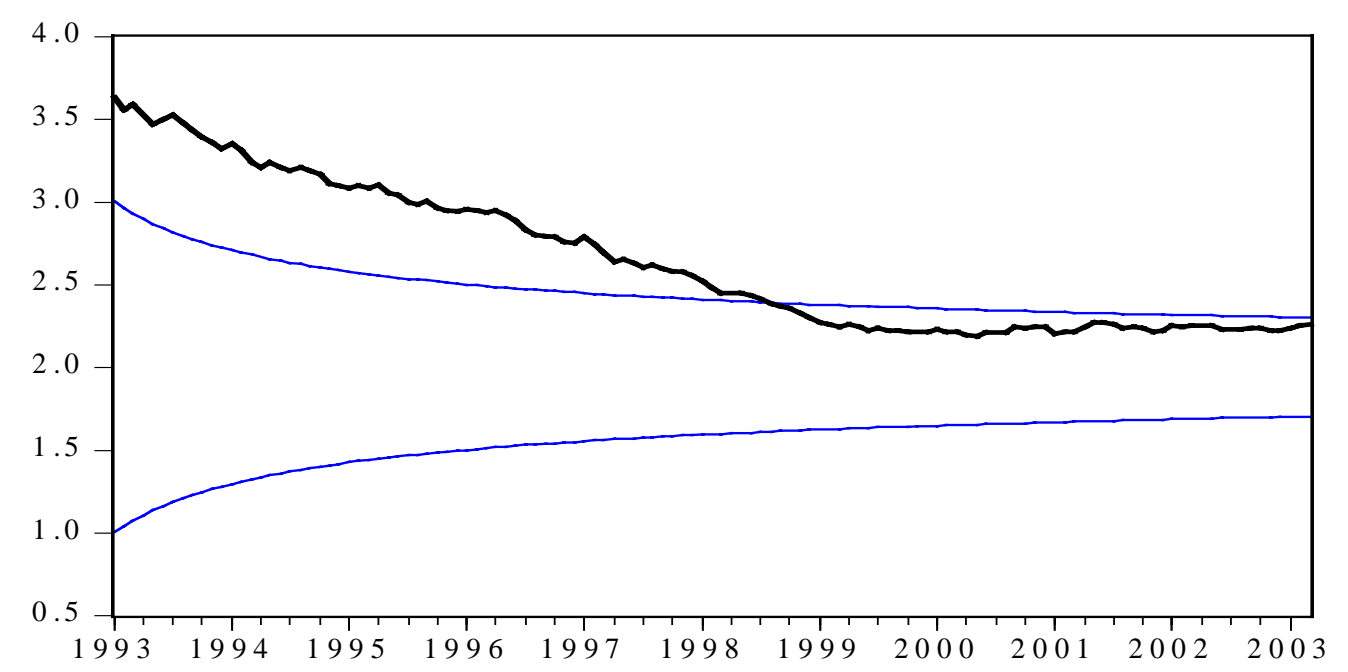

With inflation rate autocorrelation, the standard deviation of the mean inflation rate calculated over $n$ years becomes (see Crawford, 2001):

$\sigma_{\bar{\pi}}=\frac{\sigma \sqrt{1+\rho_{1}+\rho_{2}+\ldots+\rho_{n-1}}}{n}$ where $\rho_{i}$ measures the correlation between the current inflation rate, derived from the year-on-year change in prices, and the year-on-year inflation rate with a lag of $i$ years.

When this autocorrelation of euro-area inflation rates is taken into account, we can represent the confidence interval and the year-on-year changes in prices calculated from January 1998 forward, assuming that the inflation target is "close to but less than $2 \%$ ". This target is set at $1.8 \%$ by convention.

Chart 15

Mean year-on-year change centred on $1.8 \%$ since January 1998

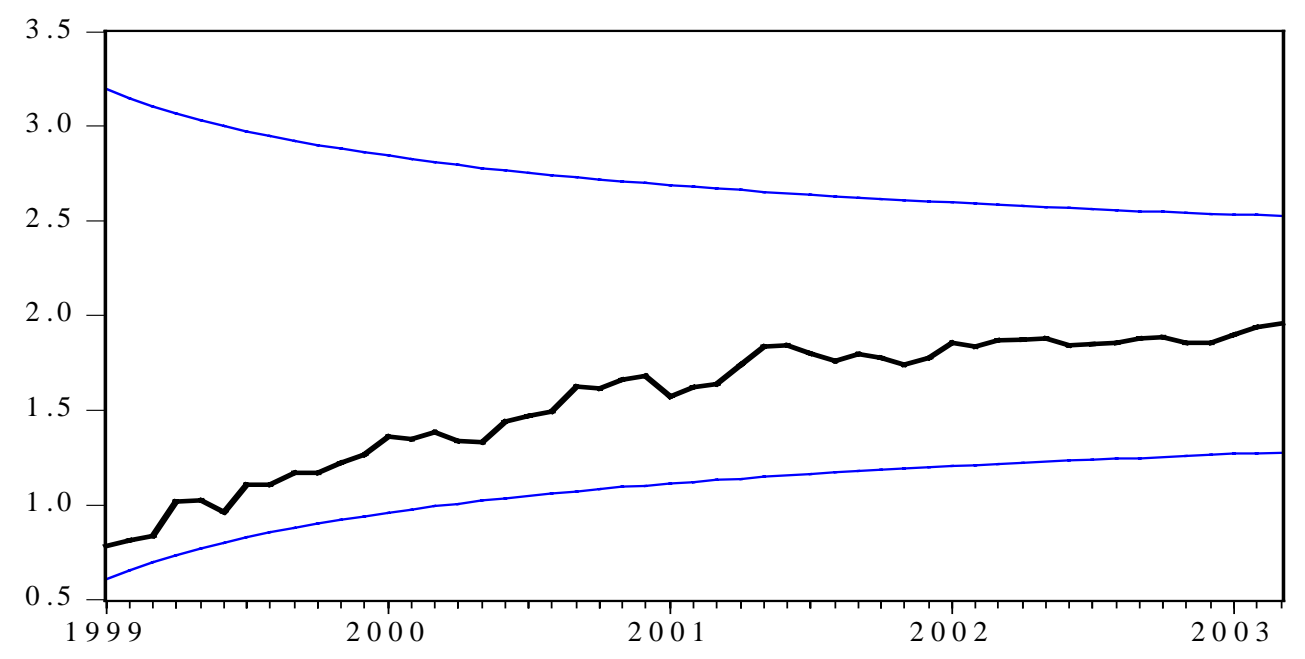


This time, the mean inflation rate always falls within the confidence interval and gradually converges towards a level slightly below $2 \%$. This level, which corresponds to the steady-state inflation rate, is equal to $1.94 \%$, as was estimated earlier.

These characteristics mean that even a temporary shock to the level of euro area inflation will have a lasting influence on price dynamics. For example, if we assume that equation (10') gives the price dynamics, then a shock equal to one standard deviation to the level of inflation will not be eliminated until seven years later, as shown in Chart 16 below.

\section{Chart 16}

One standard deviation shock to the year-on-year change in prices

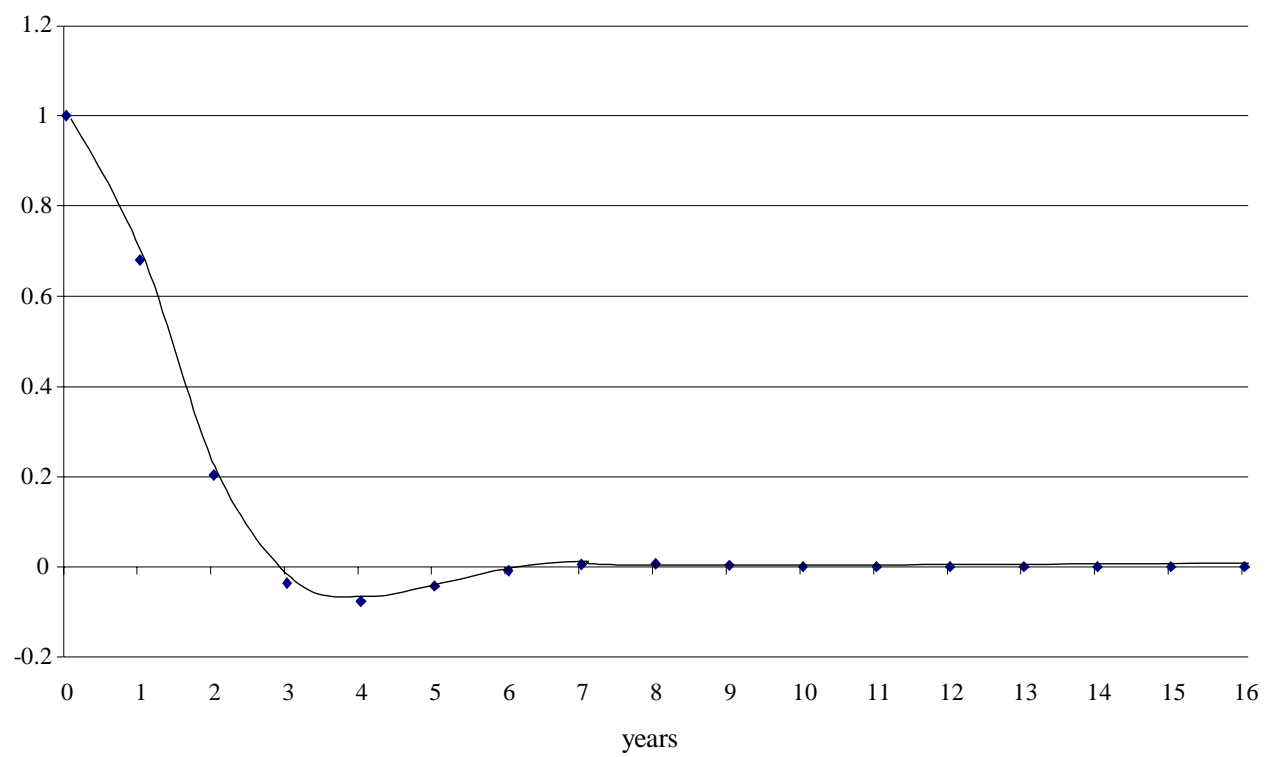

\subsubsection{Long-term inflation expectations}

When the French government launched inflation-linked Treasury bonds, which were first linked to French inflation (OATi) and then to euro area inflation (OATie), it became possible to derive a proxy measure of economic agents' mean long-term inflation expectations by calculating the break-even inflation rates, meaning the difference between nominal yields and inflation-linked yields at the same maturity. Chart 17 below shows average inflation 10 years ahead. Even though a number of biases influence this measure, and more particularly biases linked to liquidity premiums, long-term inflation expectations seem to have been contained both with regard to French inflation and to euro-area inflation. Both fall within the range from $1.5 \%$ to $2 \%$ and only rarely exceed the $2 \%$ ceiling set by the Central European Bank. 


\section{Chart 17}

Inflation expectations derived from OATi and OA Tie yields

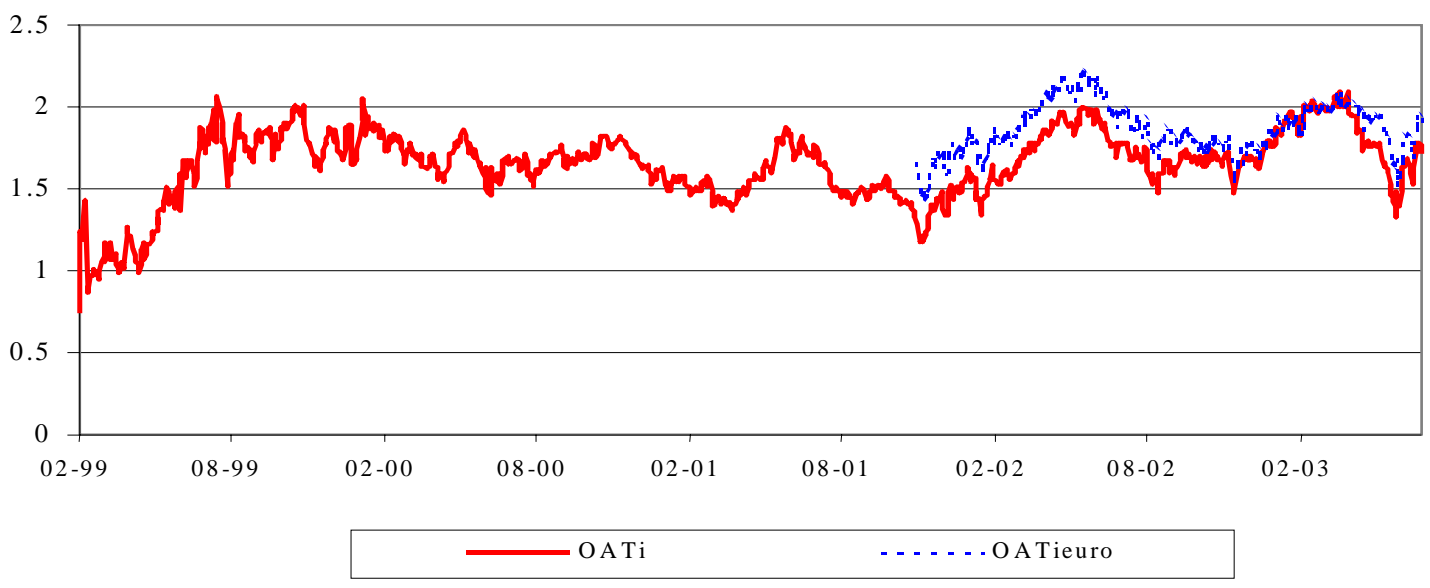

Source: Banque de France

Long-term forward interest rates on government bonds provide another measure of changes in medium- to long-term inflation expectations. More specifically, they provide better information than long-term interest rates do, since changes in the latter could be influenced by variations in short-term interest rates that are not related to inflation expectations (Kohn, 2003). The five-year forward rate starting five years ahead (denoted $i_{5,5}$ ) is used here. ${ }^{26}$ Changes in this rate between 1991 and the present are shown in Chart 18. Long-term forward rates have fallen by about three percentage points over the period as a whole. A similar pattern can be observed to varying degrees in all countries (see the chart from Kohn, 2003). Two episodes of significant rises marked the overall fall in long-term forward rates, which spiked by about two percentage points in 1994 and again in 1999. Once again, this pattern was not specific to the euro area; forward rates rose to varying degrees in all industrialised countries in 1994 and in 1999. More specifically, the rise observed in 1999 does not seem to be attributable to concern about the introduction of the single monetary policy. In any event, the stability of $i_{5,5}$ has been remarkable. It has remained within a range of 5\% to 6\% since 1999.

Chart 18

Five-year forward rate starting five years ahead (1991-2003)

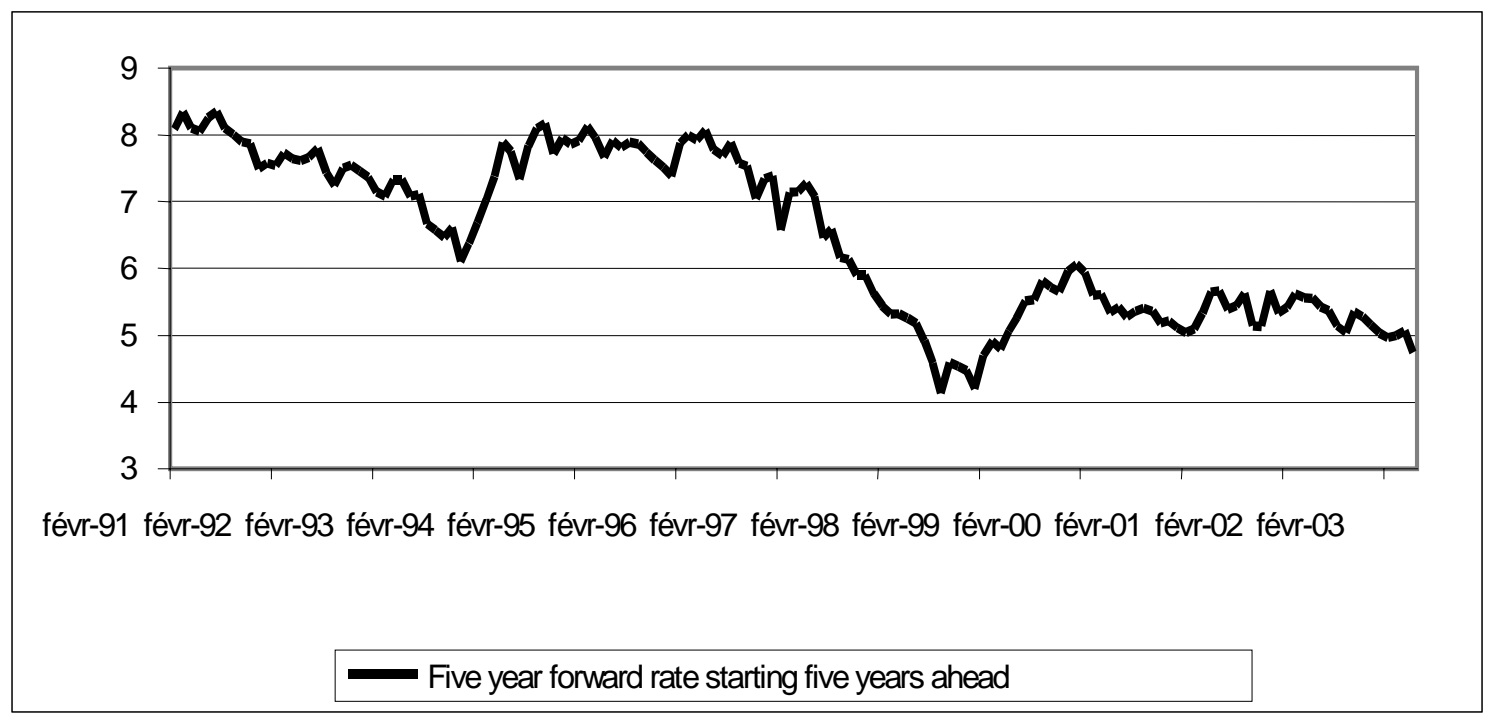

\footnotetext{
${ }^{26}$ We use the five-year and 10-year yields on German government bonds. The five-year rate starting five years ahead is calculated using the following formula: $\left(\left(\left(1+\mathrm{i}_{10}\right)^{10} /\left(1+\mathrm{i}_{5}\right)^{5}\right)^{0,2}\right)-1$. Source: Bloomberg, calculations by the authors.
} 


\subsection{Role of money in anchoring long-term expectations}

How can we explain the stability of the inflation rate and inflation expectations observed in the medium to long term in the euro area? Has the announcement of a reference value for monetary growth contributed to this stability? Many analysts have said that the answer to this last question is no on the basis of the lessons drawn from the New Keynesian theoretical model that has been used up until now. But, even if money plays no role in the determination of the short-term inflation rate, it does play a role in the medium to long term. The equilibrium inflation rate is therefore determined by achieving monetary equilibrium and it depends on the growth rate of the money supply. Before looking at this point in greater detail, it would be helpful to review the analysis of money demand behaviour.

\subsubsection{Review of money demand}

The money demand function used up until the present assumes that securities maturing during the period are the only category of assets that can be substituted for money. This assumption is much too restrictive and, in fact, a great many real and financial assets, including bonds, equities and physical capital, can be substituted for money (Friedman, 1956; Nelson 2002). In order to take this into account, we can assume that the demand for money depends on both the short-term rate and the longterm rate, which means replacing equation (7) with the following specification called the "FriedmanMeltzer type" specification (Nelson, 2002):

$$
\left.m_{t}-p_{t}=\kappa_{y} y_{t}-\kappa_{i} \mid i_{t}^{l}-i_{t}\right\rfloor+w_{t}
$$

where $i^{l}$ is the long-term rate; $\kappa_{\mathrm{y}}$ is income elasticity; $\kappa_{\mathrm{i}}$ denotes the semi-elasticity to the spread between the long-term rate and the short-term rate. Equation (7) can be rewritten using the Fisher equation, which states that:

$$
\begin{array}{ll}
\text { in the long term: } & i_{t}^{l}=r_{t}^{l}+E_{t}\left(\pi_{t}^{l}\right) \\
\text { in the short term: } & i_{t}=r_{t}+E_{t}\left(\pi_{t}\right)
\end{array}
$$

Or:

$$
\text { (7") } \quad m_{t}-p_{t}=\kappa_{y} y_{t}-\kappa_{i}\left[\left(r_{t}^{l}-r_{t}\right)+\left(E_{t}\left(\pi_{t}^{l}\right)-E_{t}\left(\pi_{t+1}\right)\right)\right]+w_{t}
$$

where $r^{l}$ is the real long-term interest rate; $r$ is the real short-term interest rate; $E_{t}\left(\pi_{t}^{l}\right)$ is the expected long-term inflation rate (i.e. between date $t$ and date $t+l$ ).

This is the specification that is usually used for econometric research on the broad M3 aggregate in the euro area (see Avouyi-Dovi et al., 2003, Coenen and Vega, 1999; Gerlach and Svensson, 1999). This research highlights a specific characteristic of the euro area, where money demand seems to be much more stable than it is in comparable economies (United States, United Kingdom and Japan). The estimated values for $\kappa_{y}$ are generally between 1.1 and 1.5 , which indicates a steadily diminishing trend in the velocity of circulation. ${ }^{27}$ The estimated values for $\kappa_{i}$ are around -0.8 (Coenen and Vega, 1999).

\footnotetext{
${ }^{27}$ Avouyi-Dovi et al. (2003) is an exception. In their estimate, the authors impose the constraint $\kappa_{\mathrm{y}}=1$.
} 


\subsubsection{Pointlessness of a monetary growth target}

There is a very widely held view that the shift from the short to medium term to the medium to long term does not change the analysis of the determination of the equilibrium inflation rate. This means that announcing a monetary growth target would not be helpful for ensuring long-term price stability. This result is demonstrated by analysing the economy's steady state using equations (1) through (6) and equation ( $\left.7^{\prime}\right)$. It is assumed that the environment includes a central bank that provides anchoring of short-term expectations, that this central bank enjoys strong credibility and that financial markets are efficient. In the economy's steady state, the expected value of real balances is equal to:

$$
\left.E\left[m_{t}-p_{t}\right]=\kappa_{y} E\left[y_{t}\right]-\kappa_{i} \mid E\left(r_{t}^{l}-r_{t}\right)+E\left[\pi_{t}^{l}\right]-E\left[\pi_{t+1}\right]\right]
$$

where E [.] corresponds to the mean value calculated over the long term. To simplify, let us assume that: 1) the interest rate is constant; 2) short-term expectations are anchored on the central bank's inflation target, in which case, (12) could be written as:

$$
E\left[m_{t}-p_{t}\right]=\kappa_{y} E\left[y_{t}\right]-\kappa_{i}\left[E\left[\pi_{t}^{l}\right]-\pi *\right]
$$

If we assume that the central bank is credible and the markets are efficient, this gives:

$$
E\left[\pi_{t}^{l}\right]=\pi *
$$

Hence the variations:

$$
E\left[\Delta m_{t}\right]-E\left[\pi_{t}\right]=\kappa_{y} E\left[\Delta y_{t}\right]
$$

In this equation, monetary growth is the only endogenous variable, if we assume that the long-term growth rate of the economy is constant $\left(g_{y}\right)$ :

$$
E\left[\Delta m_{t}\right]=\kappa_{y} \cdot g_{y}+\pi *
$$

The real GDP growth rate and the inflation target determine the long-term money-supply growth rate. From this point of view, the shift from the short to the medium term to the medium to long term does not make any difference: monitoring monetary growth is equally pointless in both cases. It is even more pointless to announce the monetary growth rate calculated with (15) as a reference value to guide private sector agents in forming their expectations. "The robustness of the long-run link between money growth and inflation and the consensus around it do not justify assigning a monetary aggregate a special status in the monetary policy strategy of a central bank, not even one that has price stability as a primary goal. The reason is simple: equation (15) is a long-run equilibrium relationship, which will hold independently of the monetary regime in place. In other words, achieving the desired inflation objective does not require paying special attention to the evolution of monetary aggregates" (Gali, 2003). Or, to put it another way: under the assumptions made, the quantity of money is endogenous and inflation targeting is an institutional device that can be used to ensure the integrity of the unit of account over time (Aglietta, 2002).

\subsubsection{Need to announce a monetary growth target}

The critique of the New Keynesian approach to the determination of the equilibrium inflation rate stresses the importance of money for ensuring long-term monetary stability (McCallum, 2001; Nelson, 2002). 
This critique is based on the following idea: contrary to the assumption made in the previous demonstration, the central bank's influence over the nominal interest rate does not operate in the same way in the short term as it does in the long term. In the short term, the central bank can influence the nominal interest rate $\left(i_{t}=r_{t}+E_{t} \pi_{t+1}\right)$ by increasing the quantity of money. This increases real balances and lowers the real interest rate $r$ and, consequently, the nominal interest rate $i$ though a liquidity effect. The liquidity effect does not come into play in the long term. The central bank cannot influence the real interest rate. Thus, its only means of action with regard to the nominal rate is to influence inflation expectations. In the steady state:

$$
E\left(i_{t}\right)=E\left(r_{t}\right)+E\left(\pi_{t}^{l}\right)
$$

The central bank's action has to be carried out through $E\left(\pi_{t}^{l}\right)$. What are the determinants of the expected inflation rate in the steady state? The Phillips Curve equation and the IS equation are of no help here..$^{28}$ On the other hand, the money market equilibrium equation provides the relationship between the mean value of the inflation rate and the mean value of the money supply growth rate, which is influenced by the central bank:

$$
\left.E\left[m_{t}-p_{t}\right]=\kappa_{y} E\left[y_{t}\right]-\kappa_{i} \mid E\left(r_{t}^{l}-r_{t}\right)+E\left[\pi_{t}^{l}\right]-E\left[\pi_{t+1}\right]\right]
$$

Contrary to the assumption made under the New Keynesian analysis, the mean value of the long-term inflation rate determines the mean value of the expected short-term inflation rate.

$$
E\left(\pi_{t+1}\right)=E\left(\pi_{t}^{l}\right)
$$

And, instead of (15), we get:

$$
E\left[\Delta m_{t}\right]=\kappa_{y} \cdot g_{y}+E\left(\pi_{t}^{l}\right)
$$

In order to anchor long-term expectations at the desired level, the central bank has to announce a money supply growth target derived using equation (15'). To ensure the overall consistency of monetary strategy, meaning consistency between expectations in the short to medium term, discussed in the second section, and the anchoring of medium- to long-term expectations, the following must hold:

$$
E\left[\Delta m_{t}\right] *=g_{M} *=\kappa_{y} \cdot g_{y}+\pi *
$$

If all of the conditions set out above hold, then long-term price-level uncertainty will be reduced and it will be stationary around a trend. This means that monetary stability will be ensured both in the short term and in the long term. The value chosen for $g_{M} *$ in the euro area is $4.5 \%$. This is derived by multiplying the estimated value of $\kappa_{y}$, which is 1.3 on average, by the medium-term trend of GDP growth $\left(2 \%<g_{y}<2.5 \%\right)$ and by adding up the parameter consistent with the definition of price stability (less than 2\% increase in the HICP) (ECB Monthly Bulletin, May 2001 . It is important to note that the reference value announced is relative to the growth of nominal balances, but to achieve stationarity of the $(\log )$ general price level around a trend, the demand for real balances $(m-p$ in equation 17) needs to be stable.

\subsection{Attempt to evaluate long-term monetary stability in the euro area}

We can evaluate the ECB's monetary strategy aimed at ensuring long-term monetary stability by examining either the results, measuring the quality of the anchoring of long-term expectations, or by

\footnotetext{
${ }^{28}$ As long as in equation (2), $\beta=1$ and $\phi=0$.
} 
examining the method used, measuring the contribution of money to the anchoring of expectations. It is obviously difficult to make such an evaluation at this time, particularly with regard to the second point, since the ECB has been operating for only four and a half years.

\subsubsection{Quality of the anchoring of long-term expectations}

A central bank's ability to anchor inflation expectations can be measured by the extent to which longterm inflation expectations respond to changes in economic agents' very-short-term inflation expectations (Kohn, 2003).

A weak response would indicate that, despite the substantial revisions of short-term expectations that can be formed in the wake of the various shocks affecting price dynamics, for example, the central bank still maintains effective control over prices in the medium to long term and thus manages to anchor long-term expectations solidly at a level that is compatible with its ultimate target.

This type of measurement can be derived from the data provided by the Consensus Forecasts, by looking at the way revisions of inflation expectations for the current year are passed onto expectations five to ten years ahead.

$\underline{\text { Table } 5}$

\section{Changes in long-term expectations in the event of a shock to short-term expectations}

\begin{tabular}{|l|c|c|c|}
\hline Mean variation of inflation expectations & Over current year (1) & $\begin{array}{c}\text { Five to ten years ahead } \\
(2)\end{array}$ & $\begin{array}{c}\text { Ratio } \\
(2) /(1)\end{array}$ \\
\hline United States & & & \\
$1990-2003$ & 42 & 10 & 0.24 \\
$1999-2003$ & 32 & 10 & 0.31 \\
\hline United Kingdom & 53 & 17 & 0.32 \\
$1990-2003$ & 22 & 10 & 0.45 \\
$1999-2003$ & 64 & 18 & \\
\hline Canada & 40 & 12 & 0.28 \\
$1990-2003$ & & & \\
$1999-2003$ & 28 & 10 & 0.30 \\
\hline Euro area & & & \\
$1999-2003$ & & & \\
\hline
\end{tabular}

Source: Consensus Economics - Banque de France Calculations. The weighted mean of inflation expectations in Germany, France, Italy and the Netherlands from 1999 to 2002 is a proxy for expected inflation in the euro area.

As the table above shows, an average of only one third of the revisions of short-term expectations are passed on to the long-term inflation expectations. In this respect, the ECB's ability to anchor inflation expectations seems to be comparable to that of other leading central banks.

It is helpful to compare the five-year forward rate starting five years ahead, shown below, to monetary policy changes reflected in the short-term rate (Chart 19). At the end of 2000 , both rates were practically equal. Today, the short-term rate is down by two percentage points, whereas the five-year forward rate starting five years ahead is still virtually unchanged from its initial value. This shows that the ECB was able to loosen monetary conditions without triggering any notable change in long-term inflation expectations. ${ }^{29}$

\footnotetext{
${ }^{29}$ Incidentally, the value of $i_{5,5}$ is higher than it was in early 1999 , which means that it shows no threat of a deflationary spiral in the medium term.
} 
Chart 19

Interbank rate and long-term rate expectations

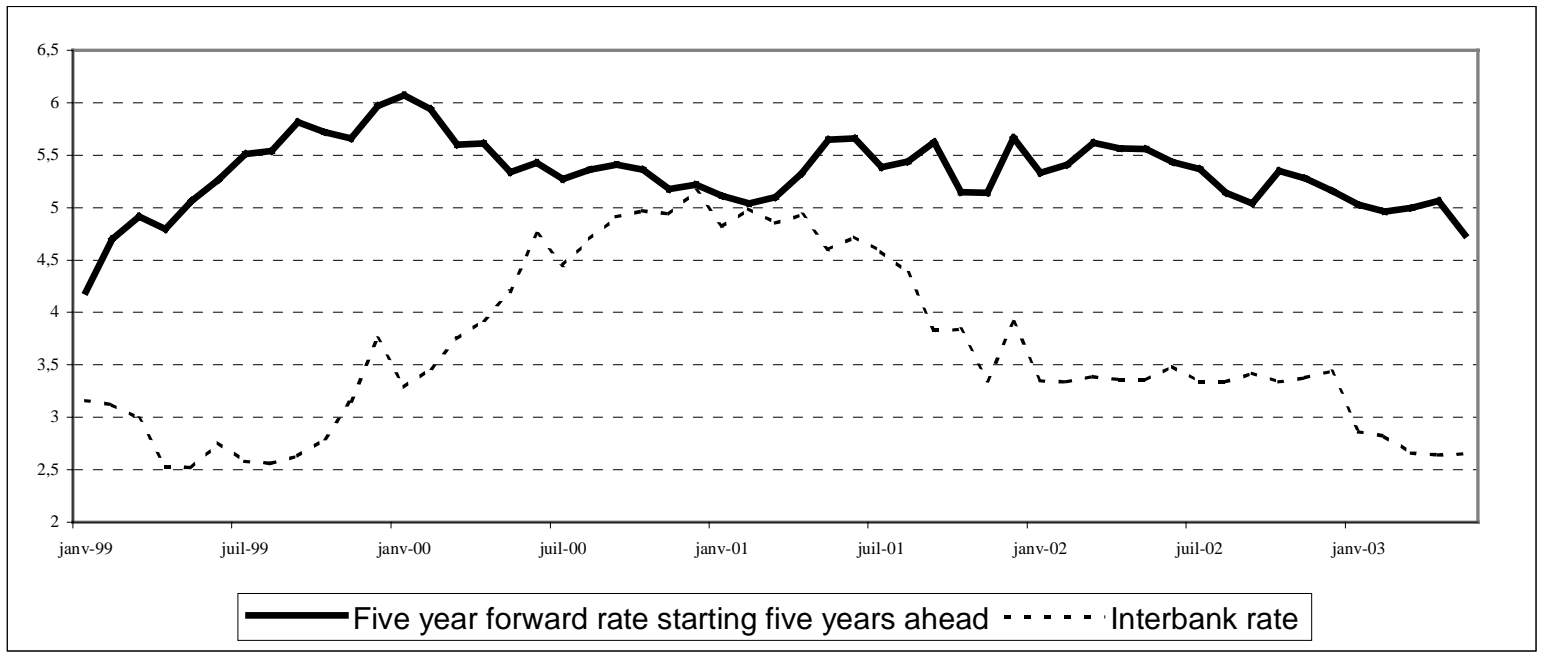

Source: Bloomberg, calculations: Banque de France
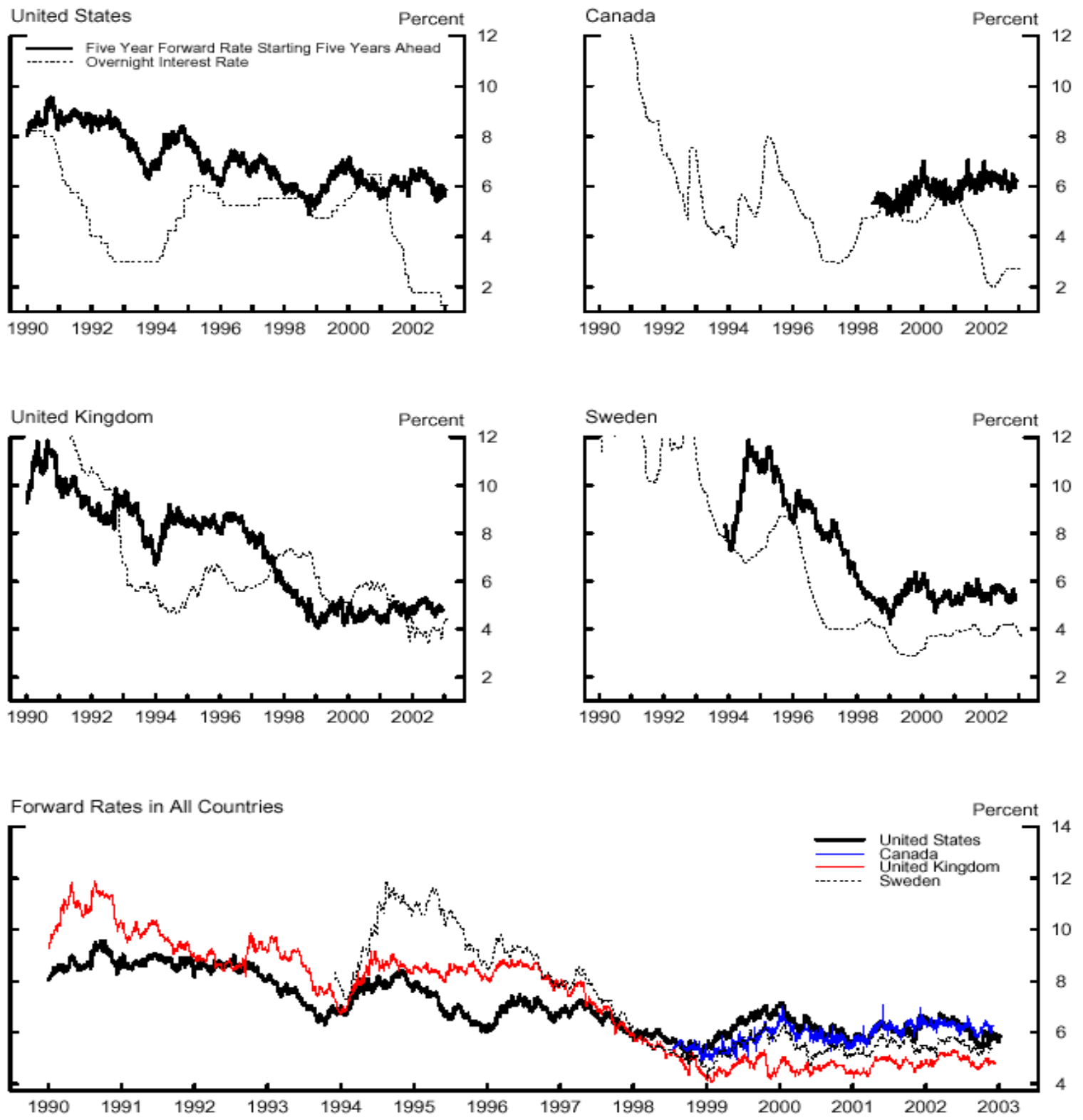

Source: Kohn, 2003. 


\subsubsection{Contribution of money to anchoring long-term expectations}

Bordo, Choudhri and Schwartz (1990) propose an indicator of long-term price-level uncertainty that is constructed using a Beveridge-Nelson decomposition. When $P^{T}{ }_{t}$ denotes the trend value of the price level at date $t$, the indicator is equal to (Cochrane, 1988):

$$
V_{n}\left(P^{T}\right)=\frac{\operatorname{var}\left(P_{t}^{T}-P_{t-n}^{T}\right)}{n}
$$

where $n$ is a large constant. This variable has an asymptotic variance that can be estimated by $(4 n / 3 T)$ $V_{n}\left(P^{T}\right)$.

It is a delicate matter to use such an approach in the euro area, primarily because of the small size of the samples available. The trend value derived using the Beveridge-Nelson decomposition ${ }^{30}$ does not capture changes in the price level very well (see Chart 20 below). However, if we limit the estimates to the period in which the ECB has been operating, the trend derived from the Beveridge-Nelson decomposition is very close to a linear trend. This result is fragile, but it tends to corroborate the reduction in price-level uncertainty since 1999 that has already been shown. The Bordo, Choudhri and Schwartz indicator, which measures variance in forecasts of the trend component of the BeveridgeNelson decomposition, diminishes sharply from $6.4 \times 10^{-6}$ over the period from 1992 to 2003 to $6.9 \times$ $10^{-9}$ since 1999 .

\section{Chart 20}

\section{Contribution of money to long-term monetary stability}

Beverige-Nelson trend and euro area HICP 1992-2003

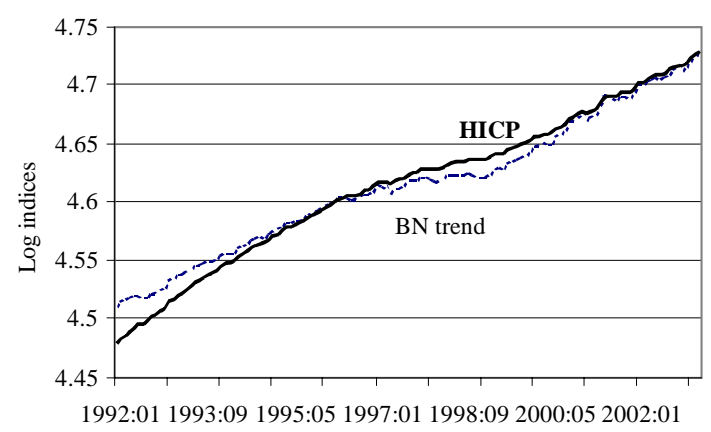

Beveridge Nelson trend and euro area HICP 1999-2003

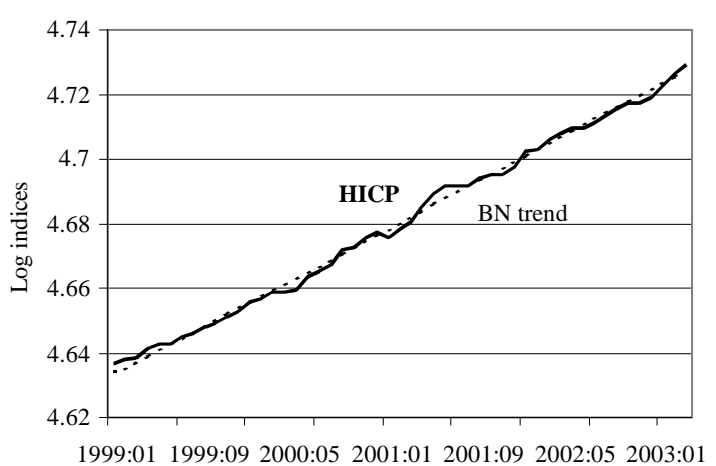

A second way of measuring the contribution that money makes to anchoring long-term inflation expectations is to run stationarity tests on the level of the HICP and the level of real balances, which are measured here as the ratio of M3 to the HICP, in order to assess to what extent these two series can be considered to be stable around a deterministic trend. In such a case, prices and real balances will only deviate from their long-term trend temporarily in the event of exogenous shocks. This statistical property implies the absence of uncertainty about the long-term price-level or the level of real balances. On the other hand, if the series are stationary in difference (I(1)), then an exogenous shock to the price level will be persistent and there will always be uncertainty about the medium- to long-term price level. These tests produced the following results in the euro area:

\footnotetext{
${ }^{30}$ This decomposition is derived from an ARIMA(1,1,1) model of the HICP estimated for the period from 1992q1-2003q3.
} 
$\underline{\text { Table } 6}$

Stationarity tests on the HICP level and real balances

\begin{tabular}{|l|l|c|c|}
\hline Variable & Test used & $1992 \mathrm{q} 1-2003 \mathrm{q} 3$ & $1999 \mathrm{q} 1-2003 \mathrm{q} 3$ \\
\hline \multirow{2}{*}{$\ln \left(\right.$ ipch $\left._{t}\right)$} & ADF & -2.4 & $-3.36^{*}$ \\
\cline { 2 - 4 } & Phillips-Perron & -3.04 & $-3.66^{* *}$ \\
\hline \multirow{2}{*}{$\ln \left(\right.$ M 3t $_{*} /$ ipch $\left._{t}\right)$} & ADF & -0.37 & -2.62 \\
\cline { 2 - 4 } & Phillips-Perron & -0.42 & -2.77 \\
\hline
\end{tabular}

These results covering the whole period from 1992 to 2003 reject the hypothesis of stationarity of the price level and real balances around a deterministic trend. Therefore, there is a high degree of longterm price-level uncertainty in the euro area. Furthermore, the non-stationarity of real balances around a long-term trend seems to indicate that a real balance growth target, like the one considered by Milton Friedman (1960), would not eliminate long-term price-level uncertainty. This conclusion seems to be in contradiction with the work done by the ECB and others on the stability of money demand in the euro area. However, it should be noted that the indicators used in this study are not the same as the ones that the ECB used in its own research, which underpins the determination of the reference value for money growth.

Furthermore, these tests were run for the whole period and they are bound to be biased by the convergence process, which may have produced atypical price dynamics in the euro area. In addition the dynamics cannot be interpreted as resulting from the implementation of the single monetary policy, even though domestic monetary policies in Europe were very closely coordinated. Thus, it would be helpful to run the tests again over the period after the ECB started its operations, even though this would mean a big reduction in the sample size and a possible bias in the results owing to the weakness of some of the tests (particularly the ADF test). The second column in Table 6 somewhat modifies the results obtained for the period as a whole. More specifically, the tests no longer reject the hypothesis of price stationarity around a deterministic trend. This could be interpreted as a great success for the ECB, meaning that it has managed to reduce or even eliminate uncertainty about the price level. On the other hand, the tests still point to the conclusion that real balances are stationary in difference. Consequently, the information currently available does not enable us to measure the exact contribution that the money growth target makes to reducing long-term price-level uncertainty.

The empirical link between inflation and money growth can also be estimated more directly. Some recent work, such as that by De Grauwe and Polan (2001), questions the link and rejects the principle first stated by Milton Friedman that "inflation is always and everywhere a monetary phenomenon". On the basis of the estimation of such a link in the euro area, it appears that the relationship between inflation and money growth is weak and insignificant, as shown in Table 7 below. More specifically, the money growth coefficient is very different from unity and not significantly different from zero.

\section{$\underline{\text { Table } 7}$}

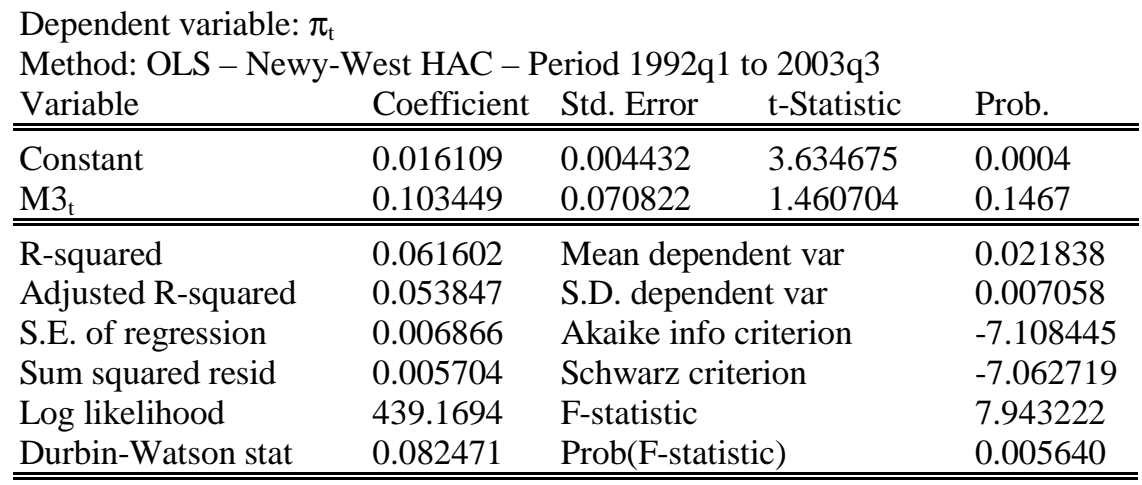


As E. Nelson (2002) pointed out, such a result cannot undermine the relevance of the relationship between money growth and prices. In fact, relationship is primarily a long-term one. And the information content of money vis-à-vis inflation is only truly relevant starting two or more years ahead. If, instead of looking at current money growth, we examine annual M3 growth lagged by two, three and four years, we end up with radically different results:

\section{$\underline{\text { Table } 8}$}

\begin{tabular}{|c|c|c|c|c|}
\hline \multicolumn{5}{|c|}{$\begin{array}{l}\text { Dependent variable: } \pi_{\mathrm{t}} \\
\text { Method: OLS - Newy-West HAC - period } 1997 q 1 \text { to } 2003 q 3\end{array}$} \\
\hline Variable & Coefficient & Std. Error & $\mathrm{t}$-Statistic & Prob. \\
\hline $\mathrm{C}$ & -0.020273 & 0.009581 & -2.115939 & 0.0379 \\
\hline $\mathrm{M} 3_{\mathrm{t}-24}$ & 0.296537 & 0.082579 & 3.590947 & 0.0006 \\
\hline $\mathrm{M} 3_{\mathrm{t}-36}$ & 0.308758 & 0.085243 & 3.622110 & 0.0005 \\
\hline $\mathrm{M} 3_{\mathrm{t}-48}$ & 0.206557 & 0.074235 & 2.782467 & 0.0069 \\
\hline R-squared & 0.370293 & Mean depen & it var & 0.018034 \\
\hline Adjusted R-squared & 0.343685 & S.D. depend & var & 0.005619 \\
\hline S.E. of regression & 0.004552 & Akaike info & erion & -7.894685 \\
\hline Sum squared resid & 0.001471 & Schwarz crit & & -7.771086 \\
\hline Log likelihood & 300.0507 & F-statistic & & 13.91693 \\
\hline Durbin-Watson stat & 0.302000 & Prob(F-statis & & 0.000000 \\
\hline
\end{tabular}

In the case of the euro area, the monetary growth coefficients are not only statistically different from zero, their cumulative sum is equal to 0.81 and no longer very far from unity in this case, in keeping with Friedman's principle. This result is also identical to the one that Nelson (2002) obtained for the United States.

\section{Conclusion}

The price-stability-oriented monetary policy strategy adopted by the European Central Bank can be qualified as a mixed or hybrid strategy: it aims to anchor medium-term inflation expectations, by ensuring that they stay within a narrow range between $1.7 \%$ and $1.9 \%$, while also attempting to restrict long-term price-level uncertainty, by announcing a reference value for the growth of the M3 monetary aggregate. Such a strategy is bound to be more difficult to explain to the public than a pure inflationtargeting strategy or a pure money-growth targeting strategy would be. Analysts who focus on the short to medium term cannot see the point of a money growth target, as they do not consider that such a target provides any useful information. Analysts who focus solely on long-term price stability cannot understand the importance attributed to short-term developments. For them, such developments are just so much noise that is difficult to interpret and not worth bothering about. In reality, these two aspects of monetary policy strategy are actually complementary. Theoretical and empirical analyses show that they form a coherent whole.

The New Keynesian framework is appropriate for analysing short- to medium-term monetary policy strategy. A policy to anchor inflation expectations is an effective instrument for ensuring monetary stability. Furthermore, money can provide helpful information about the future direction of economic activity and, to a lesser extent, about price developments. On the other hand, New Keynesian analysis cannot provide a satisfactory explanation of the anchoring of long-term inflation expectations. Money plays a decisive role in the long term and the announcement of a reference value for money supply growth has a sound theoretical basis. The construction of theoretical models to achieve coherence between New Keynesian analysis in the short to medium term and monetary analysis in the long term has long been a major objective for economic theory. Substantial progress has been made in this direction. We now have models where inflation expectations are Keynesian in the short to medium term, meaning that they are formed on the basis of a Phillips curve, and monetarist in the medium to long term, meaning that they are derived from monetary factors. These models justify the choice of a 
hybrid or a "mixed" monetary policy strategy, where the central bank focuses on both the real determinants and the monetary factors influencing the price level to ensure full anchoring of both short-term and long-term expectations. Yet, it must be acknowledged that the theoretical analysis of hybrid strategies is not as advanced as that of pure strategies. There is agreement about the effectiveness of a short-term inflation target based on New Keynesian criteria, but what would be the best supplementary device to ensure long-term price-level stability? One of the major objectives for research in coming years should be to compare the effectiveness of the various possible solutions, such as announcing a reference value for money growth, an escape clause or an error-correction mechanism.

Since the single monetary policy has been applied in the euro area, the short-term inflation dynamics has been greatly disrupted by a series of temporary price shocks, but these shocks have not affected the anchor for inflation expectations, which have remained remarkably stable in a range between $1.5 \%$ and $2 \%$. A number of points stand out with regard to the medium and long term: 1) The steady-state average annual inflation rate is about $1.9 \%$, which is "close to, but less than $2 \%$ ", but reversion to the steady state after a temporary inflation shock is still quite slow, because of the strong inertia of inflation. 2) The various measurements of long-term inflation expectations are consistent and stable, ranging from $1.5 \%$ to $2 \%$. Empirical analysis produces a fairly reassuring picture of the medium- to long-term effectiveness of the ECB's monetary policy strategy: 1) A shock that affects short-term inflation expectations usually does not have a knock-on effect on longer-term inflation expectations. 2) The stability of long-term expectations means that the ECB does not have to act particularly aggressively. 3) Since 1999, analysis has not rejected the hypothesis of price stationarity around a deterministic trend, which is a sign of long-term stability in the inflation rate and an absence of pricelevel uncertainty. But this is only a preliminary analysis after only five years of ECB operations. A more precise assessment of the long-term effectiveness of the ECB's action will take longer.

In terms of monetary policy strategy, the clarification provided at the end of the ECB Governing Council meeting on 8 May 2003 was useful in two respects in light of the conclusions of this report.

- The distinction drawn between "economic analysis", which refers to the New Keynesian analytical framework, and "monetary analysis" is a relevant one, because it makes it possible to anchor short-, medium- and long-term inflation expectations simultaneously.

- It also solves a problem in communicating and even implementing the single monetary policy strategy. This strategy was based on a presentation of the two "pillars" as alternative explanations for inflation, which could end up giving money a role in stabilising short-term expectations that it would be unable to play. In fact, the two approaches are complements to each other rather than alternatives. Money plays a decisive role in anchoring long-term inflationary expectations, while the New Keynesian framework is adequate for analysing short-term expectations.

- Finally, the anchoring of inflation expectations stemming from the announcement of the reference value and from the European Central Bank's credibility ensures that there is no long-term pricelevel uncertainty. This means that monetary policy does not necessarily have to compensate for a deviation from the inflation path in the short term, since the reversion to the equilibrium path should be achieved via the channel of expectations. 


\section{REFERENCES}

Adolfson, M. and U. Söderström (2003), "How does the inflation target affect the economy?", Bank of Sweden, Economic Review, No. 1, pp. 50-75.

Aglietta, M. (2002), "Commentaire sur les rapports de P. Artus et C. Wyplosz La Banque centrale européenne", Conseil d'Analyse économique, La documentation française, pp. 125-33.

Artus, P. (2002), "La Banque centrale européenne à l'épreuve des faits", Conseil d'analyse économique, La documentation française.

Artus, P. (?), "High equilibrium inflation rate in euro zone?", EMU Monitor - Press Release No. 9.

Asselain, J-C., B. Blancheton, C. Bordes and M-A. Sénégas (2002), "L'inflation française de 19221926 : les enseignements de la FTPL en perspective historique", Économies et Sociétés, M, No. 4, pp. 305-25.

Avouyi-Dovi, S., A. Diop, E-C. Fonteny, P. Jacquinot, J-P. Mésonnier and J.G. Sahuc (2003), "Estimation d'une fonction de demande de monnaie pour la zone euro : une synthèse des resultants", Bulletin de la Banque de France, No. 111, March, pp. 47-72.

Ball, L. (1997): “Efficient Rules for Monetary Policy”, NBER working paper 5952, March.

Ball, L. and N. Sheridan (2003), "Does inflation targeting matter?", NBER working paper 9577, March.

Baltensperger, E. (2000), "La Banque centrale européenne et sa politique monétaire", Banque nationale de Suisse, Bulletin trimestriel, No. 1, pp. 49-73.

European Central Bank (1999a), "The stability-oriented monetary policy strategy of the Eurosystem" ECB Monthly Bulletin, January, pp. 41-53.

European Central Bank (1999b), "Euro area monetary aggregates and their role in the Eurosystem's monetary policy strategy", ECB Monthly Bulletin, February, pp. 29-47.

European Central Bank (2003a), "Definition of price stability, range and point inflation targets: the anchoring of long term expectations", internal document.

European Central Bank (2003b), Press conference of 8 May, “The ECB's monetary policy strategy", available at www.ecb.int.

Bank of Japan (2003), "The role of money stock in conducting monetary policy", Quarterly Bulletin, May, pp. 151-202.

Barnett, R. and M. Engineer (2000), "When is Price-Level Targeting a Good Idea?", in Price Stability and the Long-Run Target for Monetary Policy, Proceedings of a seminar held by the Bank of Canada in June 2000.

Batini, N. and A. Yates (2001), "Hybrid inflation and price level targeting", Bank of England, Working Paper, No. 135.

Bofinger, P. (2000a), "Inflation targeting: much ado about nothing (new)", paper presented to the annual symposium, Ausschuss für Geldtheorie und Geldpolitik des Vereins für Socialpolitik. 
Bofinger, P. (2000b), "What the ECB can learn from inflation targeting", $€ \mathrm{MU}$ Watch, Deutsche Bank Research, April 14, No. 83.

Bordo, M.D., E.U. Choudhri and A.S. Schwartz (1990), "Money stock targeting, base drift and pricelevel predictability", Journal of monetary economics, March, pp. 253-72.

Brand, C., H-E. Reimers and F. Seitz (2003), "Narrow money and the business cycle:

Theoretical aspects and euro area evidence", European Central Bank, May, available at www.ecb.int .

Bruggeman, A., P. Donati and A. Warne (2003), "Is the Demand for Euro Area M3 Stable?", European Central Bank, May.

Bruneau C., O. De Bandt et A. Flageollet (2003): "Forecasting Inflation in the Euro Area", Notes d'Études et de Recherche de la Banque de France n ${ }^{\circ} 102$, May.

Bullard, J.B. and K. Mitra (2002), "Learning About Monetary Policy Rules”, Journal of Monetary Economics, No. 49, pp. 1105-1129.

Camba-Mendez, G. (2003), "The definition of price stability: choosing a price measure”,.ECB, available at www.ecb.int.

Carlstrom, C.T. and T.S. Fuerst (2001), "Monetary policy and self-fulfilling expectations: The danger of forecasts", Federal Reserve Bank of Cleveland, Quarter 1, Vol. 37, No. 1, pp. 9-19.

Castelnuovo, E., S. Nicoletti Altimari and D. Rodriguez-Palenzuela (2003), "Definition of price stability, range and point inflation targets: The anchoring of long-term expectations", ECB, available at www.ecb.int.

Christiano and Gust (2000), "The Expectations Trap Hypothesis", Federal Reserve Bank of Chicago, Economic Perspectives, Second Quarter, pp. 21-39.

Christiano, L.J. and T.J. Fitzgerald (2003), "Inflation and monetary policy in the twentieth century", Federal Reserve Bank of Chicago, Economic Perspectives, First Quarter, pp. 22-45.

Clarida, R., J. Gali and M. Gertler (1999), "The science of monetary policy: A New Keynesian perspective", NBER, WP 7147.

Clausen, J. R. (2002), "Inflation forecast targeting: a monetary policy strategy without shortcomings?", ECB, available at www.ecb.int .

Clerc, L. (2002), "Do Asset Prices Tell us Something about Future Inflation and Output in the euro area?", mimeo ECB.

Coenen, G. (2003a), "Zero lower bound: Is it a problem in the euro area?", ECB, available at www.ecb.int .

Coenen, G. (2003b), "Downward nominal wage rigidity and the long-run Phillips curve: Simulationbased evidence for the euro area", ECB, available at www.ecb.int .

Coenen, G. and J-L. Vega (1999), "The demand for M3 in the euro area", ECB Working Paper No. 6.

Crawford, A. (2001), "Predictability of Average Inflation over Long Time Horizons", Bank of Canada Review, Autumn, pp. 15-22. 
Crawford, A. and M. Kasumovich (1996), "Does inflation uncertainty vary with the level of inflation?", Working Paper No. 96-9, Bank of Canada.

De Grauwe, P. and M. Polan (2001), "Is inflation always and everywhere a monetary phenomenon?", CEPR Discussion paper No. 2841.

Diebold, F.X. and R.S. Mariano (1994), “Comparing predictive accuracy”, NBER technical Working Paper No. 169, November.

Eijffinger, C.W. (2003), "What are the prospects of a change in the ECB's monetary policy strategy?", Briefing paper on "The conduct of monetary policy and an evaluation of the economic situation in Europe- $1^{\text {st }}$ quarter 2003 for the European parliament”, February.

Fitoussi, J.P. (2003), "The ECB's monetary policy strategy and structural reforms", Briefing Paper, No. 2 - May 30, European Parliament, Committee for Economic and Monetary Affairs.

Forsells, M. and G. Kenny (2002), “The rationality of consumers' inflation expectations: Survey based evidence for the euro area", ECB Working Paper, $\mathrm{N}^{\circ} 163$.

Friedman, M. (1956), "The quantity theory of money. A restatement", in M. Friedman (ed), Studies in the quantity theory of money, University of Chicago Press, pp.3-21.

Friedman, M. (1960), A Program for Monetary Stability. New York, Fordham University Press, 1960.

Gali, J. (2003), "Monetary policy in the early years of EMU", in EMU and Economic Policy in Europe: the Challenges of the Early Years, edited by M. Buti and A. Sapir, Edward Elgar, 2003.

Gerdesmeier, D. and B. Roffia (2003): "Empirical estimates of reaction functions for the euro area", ECB working paper $\mathrm{N}^{\circ} 206$, January.

Gerlach, S. and L.E.O. Svensson (2002), "Money and inflation in the euro area: A case for monetary indicators?", CEPR Working Paper No. 3392.

Goodfriend, M. (1987), "Interest rate smoothing and price level trend-stationarity", Journal of Monetary Economics, 19, pp. 335-48.

Goodfriend, M. (1993), "Interest rate policy and the inflation scare problem: 1979-1992", Federal Reserve Bank of Richmond, Economic Quarterly, Winter, pp. 1-24.

Goodfriend, M. (2001), "Financial stability, deflation and monetary policy", Monetary and Economic Studies (Special edition), Bank of Japan, pp. 143-66.

Goodfriend, M. (2002a), "The phases of U.S. monetary policy", Federal Reserve Bank of Richmond, Economic Quarterly, Volume 88/4, Fall, pp. 1-17.

Goodfriend, M. (2002b), "Monetary policy in the new neoclassical synthesis: A primer", International Finance, 5:2, pp. 165-91.

Greenspan, A. (1989), “Statements to Congress”, Federal Reserve Bulletin, vol. 75, pp. 272-277.

Hauser, A. and A. Bridgen (2002), "Money and credit in an inflation targeting regime", Bank of England Quarterly Review, Autumn, pp. 299-307.

Hayo, B., M. J.M. Neumann and J. von Hagen (2002?), "EMU inflation: A detailed look", EMU Monitor. 
Hetzel, R.L. (1992), "Indexed Bonds as an Aid to Monetary Policy", Federal Reserve Bank of Richmond, Economic Review, Vol. 78, January/February, pp. 13-23.

Hetzel, R.L. (1993), "Quantity Theory Framework for Monetary Policy", Federal Reserve Bank of Richmond, Economic Quarterly Volume 79/3 Summer 1993

Ireland, P.N. (1993), "Price stability under long-run monetary targeting", Federal Reserve Bank of Richmond, Economic Quarterly, Volume 79/1, Winter, pp. 25- 45.

Issing, O. (2003), "Evaluation of the ECB's monetary policy strategy", European Central Bank, 8 May, available at www.ecb.int .

Issing, O., V. Gaspar, I. Angeloni and O. Tristani (2001), "Monetary policy in the euro area", Cambridge University Press.

Jaeger, A. (2002) : "The ECB's money pillar : An assessment", IMF working paper WP/03/82, April.

Jenkins, P. and B. O'Reilly (2001), "Monetary policy and the well-being of Canadians", in The longest decade: Canada in the 1990s, The review of economic performance and social progress, ed. K. Banting, A. Sharpe and F. St-Hilaire, Montréal, Institut de recherche en politiques publiques.

Kieler, M. (2003), “The ECB's inflation objective”, IMF working paper, WP/03/91.

King, M. (2002), "No money, no inflation - The role of money in the economy", Bank of England Quarterly Review, Summer, pp. 162- 77.

Klaeffing, M. and V. Perez (2003), "Inflation targets and the liquidity trap", ECB, available at www.ecb.int.

D. L. Kohn (2003), "Comments on Marvin Goodfriend's "Inflation Targeting in the United States?" at the NBER conference on Inflation targeting", January 25, available at http://www.federalreserve.gov/BoardDocs/Speeches/2003/20030324/link.

Longworth, D. (2002), "Inflation and the Macroeconomy: Changes from the 1980s to the 1990s", Bank of Canada Review, Spring, pp. 3-19.

Loyo, E. (1999), "Tight money paradox on the loose: A fiscalist hyperinflation”, working paper.

Masuch, K., S. Nicoletti-Altimari, H. Pill and M. Rostagno (2003), "The role of money in monetary policy making", European Central Bank, May.

McCallum, B.T. (1997), "Issues in the design of monetary policy rules", NBER, WP 6016.

McCallum, B.T. (2001), "Monetary policy analysis in models without money", Federal Reserve Bank of St. Louis, Review, July-August, pp. 145-59.

Mishkin, F. S. (2000), “What does price stability mean? Price level or inflation target?", working paper, November, available at http://www.ecb.int/home/conf/cbc1/cbc_mishkin.pdf

Morgan Stanley (2003), “The ECB's new strategy”, EuroTower Insights, January 6.

Morgan Stanley (2003), “New toys, same old game?”, EuroTower Insights, May 9. 
Nelson, E. (2002), "The future of monetary aggregates in monetary policy analysis", CarnegieRochester Conference, November 22-23, to be published in the Journal of Monetary Economics.

OECD (2003), "Persistence of inflation in the euro area", available at: http://www.oecd.org/pdf/M00037000/M00037580.pdf

Rodriguez-Palenzuela, D., Camba-Mendez and J.A. Garcia (2003), "Relevant economic issues concerning the optimal rate of inflation", BCE, available at www.ecb.int

Rogoff, K. (2003), “A case for inflation transparency”, Financial Times, 23 April.

Stock, J.H. and M.W. Watson (2001), "Forecasting output and inflation: the role of asset prices", NBER working paper, No. 6702.

Svensson, L.E.O. (1997), "Inflation forecast targeting: implementing and monitoring inflation targets", European Economic Review, June, pp. 1111-46.

Svensson, L.E.O. (1999), "How should monetary policy be conducted in an era of price stability", New challenges for monetary policy, Federal Reserve Bank of Kansas City.

Svensson, L.E.O. (2000), "Forward-looking monetary policy, leading indicators, and the Riksbank's Inflation report vs. The ECB's Monthly Bulletin", submitted to the European Parliament Committee on Economic and Monetary Affairs, 5 September.

Svensson, L.E.O. (2002), "A reform of the Eurosystem's monetary- policy strategy is increasingly urgent", submitted to the European Parliament Committee on Economic and Monetary Affairs, May.

Svensson, L.E.O. (2003a), "How should the Eurosystem reform its monetary strategy?", submitted to the European Parliament Committee on Economic and Monetary Affairs, February.

Svensson, L.E.O. (2003), "Comments on Edward Nelson The future of monetary aggregates in monetary policy analysis", to be published in the Journal of Monetary Economics.

Taylor, J. (1999), Monetary Policy Rules, The University of Chicago Press, Chicago and London.

Taylor, J. (2000), "Low inflation, pass-through, and the pricing power of firms", European Economic Review, 44, pp. 1389-408.

Trecroci, C. and J.L. Vega (2000): “The information content of M3 for future inflation”, ECB working paper $\mathrm{N}^{\circ} 33$, October.

Walton, D. and K. Daly (2003), “The ECB's monetary strategy review: Aligning words with actions", Goldman Sachs, Global economics paper, No. 92, May 6.

Walton, D. and K. Daly (2003), "ECB aligns words with actions", Goldman Sachs, European Weekly Analyst, 9 May, Issue 2003/19.

Wyplosz, C. (2002), "La Banque centrale européenne en quête de maturité", Conseil d'analyse économique, La documentation française. 


\section{Notes d'Études et de Recherche}

1. C. Huang and H. Pagès, "Optimal Consumption and Portfolio Policies with an Infinite Horizon: Existence and Convergence,” May 1990.

2. C. Bordes, «Variabilité de la vitesse et volatilité de la croissance monétaire : le cas français », février 1989.

3. C. Bordes, M. Driscoll and A. Sauviat, "Interpreting the Money-Output Correlation: MoneyReal or Real-Real?," May 1989.

4. C. Bordes, D. Goyeau et A. Sauviat, «Taux d'intérêt, marge et rentabilité bancaires : le cas des pays de l'OCDE », mai 1989.

5. B. Bensaid, S. Federbusch et R. Gary-Bobo, «Sur quelques propriétés stratégiques de l'intéressement des salariés dans l'industrie », juin 1989.

6. O. De Bandt, «L'identification des chocs monétaires et financiers en France : une étude empirique », juin 1990.

7. M. Boutillier et S. Dérangère, «Le taux de crédit accordé aux entreprises françaises : coûts opératoires des banques et prime de risque de défaut », juin 1990.

8. M. Boutillier and B. Cabrillac, "Foreign Exchange Markets: Efficiency and Hierarchy," October 1990.

9. O. De Bandt et P. Jacquinot, «Les choix de financement des entreprises en France: une modélisation économétrique », octobre 1990 (English version also available on request).

10. B. Bensaid and R. Gary-Bobo, "On Renegotiation of Profit-Sharing Contracts in Industry," July 1989 (English version of NER n ${ }^{\circ}$ ).

11. P. G. Garella and Y. Richelle, "Cartel Formation and the Selection of Firms," December 1990.

12. H. Pagès and H. He, "Consumption and Portfolio Decisions with Labor Income and Borrowing Constraints," August 1990.

13. P. Sicsic, «Le franc Poincaré a-t-il été délibérément sous-évalué ?», octobre 1991.

14. B. Bensaid and R. Gary-Bobo, "On the Commitment Value of Contracts under Renegotiation Constraints," January 1990 revised November 1990.

15. B. Bensaid, J.-P. Lesne, H. Pagès and J. Scheinkman, "Derivative Asset Pricing with Transaction Costs," May 1991 revised November 1991.

16. C. Monticelli and M.-O. Strauss-Kahn, "European Integration and the Demand for Broad Money," December 1991.

17. J. Henry and M. Phelipot, "The High and Low-Risk Asset Demand of French Households: A Multivariate Analysis,” November 1991 revised June 1992.

18. B. Bensaid and P. Garella, "Financing Takeovers under Asymetric Information," September 1992. 
19. A. de Palma and M. Uctum, "Financial Intermediation under Financial Integration and Deregulation," September 1992.

20. A. de Palma, L. Leruth and P. Régibeau, "Partial Compatibility with Network Externalities and Double Purchase," August 1992.

21. A. Frachot, D. Janci and V. Lacoste, "Factor Analysis of the Term Structure: a Probabilistic Approach," November 1992.

22. P. Sicsic et B. Villeneuve, «L'afflux d'or en France de 1928 à 1934 », janvier 1993.

23. M. Jeanblanc-Picqué and R. Avesani, "Impulse Control Method and Exchange Rate," September 1993.

24. A. Frachot and J.-P. Lesne, "Expectations Hypothesis and Stochastic Volatilities," July 1993 revised September 1993.

25. B. Bensaid and A. de Palma, "Spatial Multiproduct Oligopoly," February 1993 revised October 1994.

26. A. de Palma and R. Gary-Bobo, "Credit Contraction in a Model of the Banking Industry," October 1994.

27. P. Jacquinot et F. Mihoubi, «Dynamique et hétérogénéité de l'emploi en déséquilibre », septembre 1995.

28. G. Salmat, «Le retournement conjoncturel de 1992 et 1993 en France : une modélisation VAR », octobre 1994.

29. J. Henry and J. Weidmann, "Asymmetry in the EMS Revisited: Evidence from the Causality Analysis of Daily Eurorates," February 1994 revised October 1994.

30. O. De Bandt, "Competition Among Financial Intermediaries and the Risk of Contagious Failures," September 1994 revised January 1995.

31. B. Bensaid et A. de Palma, «Politique monétaire et concurrence bancaire », janvier 1994 révisé en septembre 1995.

32. F. Rosenwald, «Coût du crédit et montant des prêts : une interprétation en terme de canal large du crédit », septembre 1995.

33. G. Cette et S. Mahfouz, «Le partage primaire du revenu: constat descriptif sur longue période », décembre 1995.

34. H. Pagès, "Is there a Premium for Currencies Correlated with Volatility? Some Evidence from Risk Reversals," January 1996.

35. E. Jondeau and R. Ricart, "The Expectations Theory: Tests on French, German and American Euro-rates," June 1996.

36. B. Bensaid et O. De Bandt, «Les stratégies "stop-loss": théorie et application au Contrat Notionnel du Matif », juin 1996.

37. C. Martin et F. Rosenwald, «Le marché des certificats de dépôts. Écarts de taux à l'émission : l'influence de la relation émetteurs-souscripteurs initiaux », avril 1996. 
38. Banque de France - CEPREMAP - Direction de la Prévision - Erasme - INSEE - OFCE, « Structures et propriétés de cinq modèles macroéconomiques français », juin 1996.

39. F. Rosenwald, "L'influence des montants émis sur le taux des certificats de dépôts », octobre 1996.

40. L. Baumel, «Les crédits mis en place par les banques AFB de 1978 à 1992 : une évaluation des montants et des durées initiales », novembre 1996.

41. G. Cette et E. Kremp, «Le passage à une assiette valeur ajoutée pour les cotisations sociales : Une caractérisation des entreprises non financières "gagnantes" et "perdantes" ", novembre 1996.

42. S. Avouyi-Dovi, E. Jondeau et C. Lai Tong, «Effets "volume", volatilité et transmissions internationales sur les marchés boursiers dans le G5 », avril 1997.

43. E. Jondeau et R. Ricart, «Le contenu en information de la pente des taux : Application au cas des titres publics français », juin 1997.

44. B. Bensaid et M. Boutillier, «Le contrat notionnel : efficience et efficacité », juillet 1997.

45. E. Jondeau et R. Ricart, «La théorie des anticipations de la structure par terme : test à partir des titres publics français », septembre 1997.

46. E. Jondeau, «Représentation VAR et test de la théorie des anticipations de la structure par terme », septembre 1997.

47. E. Jondeau et M. Rockinger, «Estimation et interprétation des densités neutres au risque : Une comparaison de méthodes », octobre 1997.

48. L. Baumel et P. Sevestre, «La relation entre le taux de crédits et le coût des ressources bancaires. Modélisation et estimation sur données individuelles de banques », octobre 1997.

49. P. Sevestre, "On the Use of Banks Balance Sheet Data in Loan Market Studies : A Note," October 1997.

50. P.-C. Hautcoeur and P. Sicsic, "Threat of a Capital Levy, Expected Devaluation and Interest Rates in France during the Interwar Period,” January 1998.

51. P. Jacquinot, «L'inflation sous-jacente à partir d'une approche structurelle des VAR : une application à la France, à l'Allemagne et au Royaume-Uni », janvier 1998.

52. C. Bruneau et $\mathrm{O}$. De Bandt, «La modélisation VAR structurel : application à la politique monétaire en France », janvier 1998.

53. C. Bruneau and E. Jondeau, "Long-Run Causality, with an Application to International Links between Long-Term Interest Rates," June 1998.

54. S. Coutant, E. Jondeau and M. Rockinger, "Reading Interest Rate and Bond Futures Options' Smiles: How PIBOR and Notional Operators Appreciated the 1997 French Snap Election," June 1998.

55. E. Jondeau et F. Sédillot, «La prévision des taux longs français et allemands à partir d'un modèle à anticipations rationnelles », juin 1998. 
56. E. Jondeau and M. Rockinger, "Estimating Gram-Charlier Expansions with Positivity Constraints," January 1999.

57. S. Avouyi-Dovi and E. Jondeau, "Interest Rate Transmission and Volatility Transmission along the Yield Curve," January 1999.

58. S. Avouyi-Dovi et E. Jondeau, «La modélisation de la volitilité des bourses asiatiques », janvier 1999.

59. E. Jondeau, «La mesure du ratio rendement-risque à partir du marché des euro-devises », janvier 1999.

60. C. Bruneau and O. De Bandt, "Fiscal Policy in the Transition to Monetary Union: A Structural VAR Model," January 1999.

61. E. Jondeau and R. Ricart, "The Information Content of the French and German Government Bond Yield Curves: Why Such Differences?,” February 1999.

62. J.-B. Chatelain et P. Sevestre, «Coûts et bénéfices du passage d'une faible inflation à la stabilité des prix », février 1999.

63. D. Irac et P. Jacquinot, «L'investissement en France depuis le début des années 1980 », avril 1999.

64. F. Mihoubi, «Le partage de la valeur ajoutée en France et en Allemagne », mars 1999.

65. S. Avouyi-Dovi and E. Jondeau, "Modelling the French Swap Spread," April 1999.

66. E. Jondeau and M. Rockinger, "The Tail Behavior of Stock Returns: Emerging Versus Mature Markets," June 1999.

67. F. Sédillot, «La pente des taux contient-elle de l'information sur l'activité économique future ?», juin 1999.

68. E. Jondeau, H. Le Bihan et F. Sédillot, «Modélisation et prévision des indices de prix sectoriels », septembre 1999.

69. H. Le Bihan and F. Sédillot, "Implementing and Interpreting Indicators of Core Inflation: The French Case," September 1999.

70. R. Lacroix, "Testing for Zeros in the Spectrum of an Univariate Stationary Process: Part I," December 1999.

71. R. Lacroix, "Testing for Zeros in the Spectrum of an Univariate Stationary Process: Part II," December 1999.

72. R. Lacroix, "Testing the Null Hypothesis of Stationarity in Fractionally Integrated Models," December 1999.

73. F. Chesnay and E. Jondeau, "Does correlation between stock returns really increase during turbulent period?," April 2000.

74. O. Burkart and V. Coudert, "Leading Indicators of Currency Crises in Emerging Economies," May 2000.

75. D. Irac, "Estimation of a Time Varying NAIRU for France," July 2000. 
76. E. Jondeau and H. Le Bihan, "Evaluating Monetary Policy Rules in Estimated ForwardLooking Models: A Comparison of US and German Monetary Policies," October 2000 .

77. E. Jondeau and M. Rockinger, "Conditional Volatility, Skewness, ans Kurtosis: Existence and Persistence," November 2000.

78. P. Jacquinot et F. Mihoubi, «Modèle à Anticipations Rationnelles de la COnjoncture Simulée : MARCOS », novembre 2000.

79. M. Rockinger and E. Jondeau, "Entropy Densities: With an Application to Autoregressive Conditional Skewness and Kurtosis," January 2001.

80. B. Amable and J.-B. Chatelain, "Can Financial Infrastructures Foster Economic Development?,"January 2001.

81. J.-B. Chatelain and J.-C. Teurlai, “Pitfalls in Investment Euler Equations,” January 2001.

82. M. Rockinger and E. Jondeau, "Conditional Dependency of Financial Series: An Application of Copulas," February 2001.

83. C. Florens, E. Jondeau and H. Le Bihan, "Assessing GMM Estimates of the Federal Reserve Reaction Function," March 2001.

84. J.-B. Chatelain, "Mark-up and Capital Structure of the Firm facing Uncertainty," June 2001.

85. B Amable, J.-B. Chatelain and O. De Bandt, "Optimal capacity in the Banking Sector and Economic Growth," June 2001.

86. E. Jondeau and H. Le Bihan, "Testing for a Forward-Looking Phillips Curve. Additional Evidence from European and US Data," December 2001.

87. G. Cette, J. Mairesse et Y. Kocoglu, «Croissance économique et diffusion des TIC : le cas de la France sur longue période (1980-2000)», décembre 2001.

88. D. Irac and F. Sédillot, "Short Run Assessment of French Economic activity Using OPTIM," January 2002.

89. M. Baghli, C. Bouthevillain, O. de Bandt, H. Fraisse, H. Le Bihan et Ph. Rousseaux, «PIB potentiel et écart de PIB : quelques évaluations pour la France», juillet 2002.

90. E. Jondeau and M. Rockinger, "Asset Allocation in Transition Economies," October 2002.

91. H. Pagès and J.A.C Santos, "Optimal Supervisory Policies and Depositor-Preferences Laws," October 2002.

92. C. Loupias, F. Savignac and P. Sevestre, "Is There a Bank Lending Channel in France ? Evidence from Bank Panel Data," November 2002.

93. M. Ehrmann, L. Gambacorta, J. Martínez-Pagés, P. Sevestre and A. Worms, "Financial systems and The Role in Monetary Policy transmission in the Euro Area," November 2002.

94. S. Avouyi-Dovi, D. Guégan et S. Ladoucette, « Une mesure de la persistance dans les indices boursiers », décembre 2002. 
95. S. Avouyi-Dovi, D. Guégan et S. Ladoucette, "What is the Best Approach to Measure the Interdependence between Different Markets? ," December 2002.

96. J.-B. Chatelain and A. Tiomo, "Investment, the Cost of Capital and Monetray Policy in the Nineties in France: A Panel Data Investigation," December 2002.

97. J.-B. Chatelain, A. Generale, I. Hernando, U. von Kalckreuth and P. Vermeulen, "Firm Investment and Monetary Policy Transmission in the Euro Area," December 2002.

98. J.-S. Mésonnier, «Banque centrale, taux de l'escompte et politique monétaire chez Henry Thornton (1760-1815) », décembre 2002.

99. M. Baghli, G. Cette et A. Sylvain, «Les déterminants du taux de marge en France et quelques autres grands pays industrialisés : Analyse empirique sur la période 1970-2000», janvier 2003.

100. G. Cette and C. Pfister, "The Challenges of the "New Economy" for Monetary Policy," January 2003.

101. C. Bruneau, O. De Bandt, A. Flageollet and E. Michaux, "Forecasting Inflation using Economic Indicators: the Case of France," May 2003.

102. C. Bruneau, O. De Bandt and A. Flageollet, "Forecasting Inflation in the Euro Area," May 2003.

103. E. Jondeau and H. Le Bihan, "ML vs GMM Estimates of Hybrid Macroeconomic Models (With an Application to the "New Phillips Curve")," September 2003.

104. J. Matheron and T.-P. Maury, "Evaluating the Fit of Sticky Price Models," January 2004.

105. S. Moyen and J.-G. Sahuc, "Incorporating Labour Market Frictions into an Optimising-Based Monetary Policy Model,” January 2004.

106. M. Baghli, V. Brunhes-Lesage, O. De Bandt, H. Fraisse et J.-P. Villetelle, «MASCOTTE :

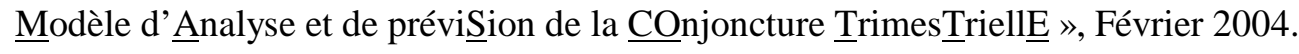

107. E. Jondeau and M. Rockinger, "The bank Bias: Segmentation of French Fund Families," February 2004.

108. E. Jondeau and M. Rockinger, "Optimal Portfolio Allocation Under Higher Moments," February 2004.

109. C. Bordes and L. Clerc, "Price Stability and the ECB's Monetary Policy Strategy," March 2004.

Pour tous commentaires ou demandes sur les Notes d'Études et de Recherche, contacter la bibliothèque du Centre de recherche à l'adresse suivante :

For any comment or enquiries on the Notes d'Études et de Recherche, contact the library of the Centre de recherche at the following address : 
email : thierry.demoulin@banque-france.fr 